\title{
Performance Enhancement of a Hybrid Renewable Energy System Accompanied with Energy Storage Unit Using Effective Control System
}

\author{
Mahmoud A. Mossa ${ }^{\text {a,c, }, 1, *}$, Olfa Gam ${ }^{\text {b,2, }}$, Nicola Bianchi ${ }^{\text {c,3 }}$ \\ ${ }^{a}$ Electrical Engineering Department-Faculty of Engineering-Minia University-Minia 61111, Egypt \\ ${ }^{\text {b }}$ Département École de Genie, Université Québéc en Abitibi Témiscamingue, Rouyn-Noranda, QC J9X 5E4, Canada \\ ${ }^{c}$ Department of Industrial Engineering, University of Padova, Via Gradenigo 6/a, 35131 Padova, Italy \\ ${ }^{1}$ mahmoud_a_mossa@mu.edu.eg; ${ }^{2}$ gamo01@uqat.ca; ${ }^{3}$ nicola.bianchi@unipd.it \\ * Corresponding Author
}

\section{ARTICLE INFO}

\section{Article history}

Received February 07, 2022

Revised February 27, 2022

Accepted February 28, 2022

\section{Keywords}

Hybrid System;

Predictive Control;

Battery Storage;

Wind Generation;

PV System

\begin{abstract}
The current study aims to present a detailed analysis of a hybrid renewable energy system used for standalone operation. The hybrid system consists of a wind-driven synchronous generator, a photovoltaic solar system, and a battery storage system. The modeling of each system component is presented and described in detail. To achieve optimal energy exploitation, the maximum power point tracking algorithm is adopted. The management of synchronous generator operation is achieved through controlling the machine-side converter using a newly formulated predictive control scheme. To visualize the advantages of the proposed control algorithm, its performance is compared with the other two traditional predictive control approaches, mainly the model predictive direct power control and model predictive direct torque control systems. An effective control scheme is also adopted to manage the power storage in the battery using a bi-directional DC/DC converter. To maintain a balanced power flow between the system units, an energy management strategy is presented. Extensive tests are carried out to evaluate the performance of the hybrid system considering variable wind speed, variable sun irradiation, and variable load profiles. The obtained results for the synchronous generator performance visualize the validity and superiority of the proposed control scheme over the other two classic controllers. The results are also validating the effectiveness of the battery storage control system and confirming the validity of the constructed energy management strategy in achieving the energy balance between the system units.
\end{abstract}

This is an open-access article under the CC-BY-SA license.

\section{Nomenclature}

$\begin{array}{clcl}\text { PMSG } & \text { Permanent magnet synchronous generator } & P_{g}, P_{g}^{*} & \text { Actual and reference active generator powers } \\ \text { MPPT } & \text { Maximum power point tracking } & Q_{g}, Q_{g}^{*} & \text { Actual and reference reactive generator powers } \\ \text { MPP } & \text { Maximum power point } & P_{g, r a t}, Q_{g, r a t} & \text { Rated active and reactive powers of the PMSG } \\ \text { PAC } & \text { Pitch angle control } & T_{g, r a t}, \psi_{g, r a t} & \text { Rated torque and flux of the PMSG } \\ \text { DFIG } & \text { Doubly fed induction generator } & P_{D C}, P_{L} & \text { DC link and load powers } \\ \text { MPC } & \text { Model predictive control } & T_{t}, T_{g} & \text { Turbine and generator torques. }\end{array}$




\begin{tabular}{|c|c|c|c|}
\hline MP DPC & Model predictive direct power control & $p$ & Pole pairs number \\
\hline MP DTC & Model predictive direct torque control & $\psi_{g}$ & Generator flux \\
\hline DPC & Direct power control & $\psi_{f}$ & Permanent magnet flux \\
\hline DTC & Direct torque control & $i_{d s}, i_{q s}$ & D-q components of generator stator current \\
\hline HRES & Hybrid renewable energy system & $V_{d s}, V_{q s}$ & D-q components of generator stator voltage \\
\hline PV system & Photovoltaic system & $\mathrm{C}$ & DC link capacitance \\
\hline THD & Total harmonics distortion & $C_{b u}, C_{s u}$ & Bulk and surface capacitances of the battery \\
\hline PWM & Pulse width modulation & $R_{s u}, R_{e}, R_{t}$ & Surface, end and terminal resistances of the battery \\
\hline SVPWM & Space vector pulse width modulation & $V_{b}, V_{c b}, V_{c s}$ & $\begin{array}{l}\text { Battery voltage, bulk and surface capacitance } \\
\text { voltages }\end{array}$ \\
\hline FCS & Finite control set & $I_{b}, I_{b u}, I_{s u}$ & Battery, bulk and surface currents \\
\hline MSC & Machine side converter & $Q_{r}$ & Battery rated capacity \\
\hline SOC & State of charge & $S O C_{o}$ & Initial battery SOC \\
\hline DOD & Depth of discharge & $\eta_{b}$ & Battery efficiency \\
\hline EMS & Energy management strategy & $I_{g}, I_{d c}, I_{L}$ & $\begin{array}{l}\text { Modulated generator current, DC link and load } \\
\text { currents, respectively }\end{array}$ \\
\hline$\beta$ & Blade pitch angle & $w_{c}$ & Weighting factor \\
\hline$\lambda$ & Tip speed ratio & $I_{p h}$ & Direct current of PV cell \\
\hline$\lambda_{\text {opt }}$ & Optimal tip speed ratio & $R_{p}, R_{s e}$ & Shunt and series resistances of PV cell \\
\hline$\Omega_{w}$ & Wind speed & $N_{p}, N_{s}$ & Parallel and series PV strings \\
\hline$\Omega_{w, n o m}$ & Nominal wind speed & $V_{P V_{c}}, I_{P V_{c}}$ & Voltage and current of PV cell \\
\hline$C_{p}$ & Turbine power coefficient & $I_{o}$ & Diode reverse saturation current \\
\hline$C_{p, \max }$ & Maximum turbine power coefficient & $q$ & Electron charge \\
\hline$P_{t}$ & Turbine power & $f$ & Diode ideality factor \\
\hline$P_{t, \max }$ & Maximum turbine power & $T$ & PV cell temperature \\
\hline$P_{w}$ & Wind power & $B$ & Boltzman's constant \\
\hline$J_{t}, J_{g}, \mathrm{~J}$ & Turbine, generator and combined inertias & $I_{s c}$ & Short circuit current of PV cell \\
\hline$F$ & Friction coefficient & $S_{r}$ & Solar irradiation \\
\hline$R$ & Generator stator resistance & $T_{i}$ & Temperature coefficient \\
\hline$L_{s}$ & Generator stator inductance & $P_{g}, P_{b}, P_{P V}$ & Generator, battery and PV power \\
\hline$\Omega_{g}$ & Generator shaft speed & $\delta$ & Generator torque angle \\
\hline$\Omega_{s}$ & Generator electrical speed & $T_{s}$ & Sampling time \\
\hline
\end{tabular}

\section{Introduction}

The depletion of natural fossil fuels magnified the need to search and utilize renewable energy sources such as wind, solar and geothermal [1][2]. Renewable energy systems with their different forms can be used in individual or hybrid nature. However, due to the dependency of these renewable energy systems on the weather, the hybrid renewable energy systems (HRES) were given priority. The hybrid systems provide higher reliability and cover higher load ratings [3][4]. Generally, the hybrid renewable system consists of more than one generation unit, such as wind and photovoltaic solar systems, in addition to the converter topologies and their relevant control systems [5]. In order to enlarge the benefit from these hybrid systems, especially in remote areas, usually additional energy storage layouts are used [6][7]. The storage systems come in the forms of batteries, flywheels, supercapacitors, and fuel cells [8].

Up till now, the HRES configurations have been the objective study of plenty of research introduced in the literature. Nonetheless, the majority of the research studies focused on the operation states of HRES systems with simple topologies. The research was limited to a small number of operation modes and took into account simple control techniques. The presented studies in [9-11] described the categories and architectures of HRES systems. The studies in [1][10][11] described the optimization approaches for scaling HRES components. A hybrid PV/wind/battery/supercapacitor system was investigated in [12]. The authors in [7][10] investigated HRES systems for stand-alone operation with DC loads; meanwhile, the HRES systems with AC loads were studied in [6][13]. Several studies focused on the HRES system's operation in a stand-alone mode [7][8][13], but on the 
other hand, they didn't consider the energy management strategies [2][6][8][10][13-17]. The majority of articles [6][10][12-16] investigated a hybrid system with a simple topology of machine side converter (MSC) coupled to a PMSG; while considering the PV as the second energy source. The MSC converter is modeled as a three-phase diode rectifier in cascade mode with a DC/DC boost controller. HRES operation with sophisticated energy storage systems such as fuel cells, hydrogen technologies, supercapacitors, and bioreactors has also been examined by some authors in [8][12][13][18][19]. Despite the fact that there is a substantial quantity of literature on HRES systems and their applications, the challenges surrounding HRES systems can still be regarded as an undeveloped technology that requires further investigation.

Further study investigation on the HRES can be performed through incorporating effective energy management and storage systems. The goal of the energy management strategy (EMS) is to achieve a balance between the produced energy and the energy demanded by the electrical loads and energy storage while preventing the storage systems from overcharging or discharging, which contributes to saving the life of the energy storage system. The investigation can also be presented in the form of designing new control topologies for different system units that can provide better performance compared with the already used types. For the wind generation system, different machine types were used, starting with self-excited induction generators with squirrel-cage rotor types [20][21], which had the advantages of robustness and low maintenance requirements. But on the other hand, they suffered from the need for a separate excitation source. After that, the doubly-fed induction generator (DFIG) came into consideration [22-25], which possessed several merits, such as using power converters with a lower rating which saves the cost, in addition to the ability to ride through the fault occurrence. However, the DFIG suffered from the high maintenance cost and reduced efficiency due to the copper losses. After that, the synchronous generators with their different configurations are paid great concern due to high robustness and high efficiency [26][27].

Regardless of the used generator type with the wind turbine system, the main factor which outlines the generator dynamics is the used control system. Different controllers were used with the synchronous generator in HRES. They are starting with the vector control [28][29], which proved its effectiveness in handling the nonlinearity in the generator model, achieving decoupled control of active and reactive powers. However, the control complexity and the delayed dynamic response were the most relevant shortages of vector control. After that, direct torque control (DTC) was proposed to solve some shortages in vector control [30][31]. The DTC provided a simpler control structure and faster dynamic response, but on the other hand, the high ripples were the most challenging item. The direct power control (DPC) is another control topology adopted as a transpose of the DTC in which two-hysteresis-based active and reactive power controllers replaced the operation of torque and flux controllers of the DTC [32-34]. The DPC shared the same disadvantages as the DTC. To attempt to overcome the shortages of vector control, DPC and DTC approach, the model predictive control (MPC) came into consideration [35][36]. The MPC has several merits such as flexibility, the ability to handle several objectives at the same time, and work without modulators such as PWM, which simplifies the control structure. The main operation of the MPC stands on formulating a convergence condition or cost function, which consists of the control terms that need to be fulfilled. For example, the model predictive DPC (MP DPC) replaced the hysteresis power controllers in classic DPC with only cost function consisting of the absolute errors between the reference and actual powers [37]. The same concept was considered with the model predictive DTC, in which a cost function combines the absolute errors of the torque and flux values [38]. A performance improvement was achieved using the MP DPC and MP DTC compared with the classic vector control, DTC, and DPC approach. This was observed through maintaining a fast dynamic response while exhibiting low ripples and a simple control structure as well. However, the MPC schemes suffered from some shortages, such as the high computation burdens; additionally, the ripples are not completely suppressed. The high computation burden of the predictive controller originates from the time taken to evaluate the cost function with its different terms. For example, in the MP DPC, the convergence condition needs to compute the predicted signals of the active and reactive powers, which are basically parameters dependents. The same thing exists in the MP DTC, in which to calculate the cost function, the torque and flux need to 
be firstly predicted. All of these computations add to the execution time of the code. On the other hand, the ripples in the MP DPC and MP DTC can be referred to for many reasons: one of them is that both MP DPC and MP DTC are using only one voltage vector in the sampling interval whatever the dynamics of the controlled variables are. This action is not precise, as it may happen that the dynamics change within the same interval, and applying the same voltage vector results in increasing the ripples. Another explanation originates from using a weighting value in the cost function [39]; this value is usually used to achieve a balance between the control terms. The selection of the weighting value is a sensitive process that must be carried out carefully. Some attempts were made to optimally tune the weighting values during the code operation [40]. However, the computation burdens were affected. Other attempts were also made to apply more than one voltage vector during the same sampling time, and the ripples were effectively suppressed however the computation burdens were also affected.

Thus, formulating a cost function with terms not requiring high computation and also not utilizing a weighting value became a challenge. For this purpose, the current study proposes an effective predictive control scheme to manage the operation of the wind-driven PMSG, which uses a cost function of similar terms that exhibit a much lower computation burden as well. The proposed cost function consists of the absolute deviations between the reference and actual generator voltage components. The actual voltages are obtained with the help of the finite control set (FCS) principle, which avoids the usage of PWM modulators; meanwhile, the reference voltage components are generated in a systematic manner depending on the deadbeat theory. Consequently, the formulated predictive control is simpler and computationally effective as well. A dynamic performance comparison between the three controllers for the PMSG used in the HRES is introduced to clarify and approve the superiority of the designed predictive controller. Additionally, an effective energy management strategy (EMS) is incorporated to achieve the power exchange balance. Furthermore, the design of the battery storage control system and PV converter are also presented and described.

In brief, the contributions that the paper introduces to the literature can be summarized as follows:

- A detailed analysis for a hybrid renewable energy system (HRES) used for standalone operation is introduced.

- The construction and modeling of the entire system are performed in a systematic manner.

- The control design for each system component is described in detail. In addition, an effective predictive control scheme is formulated and used for enhancing the PMSG dynamics.

- A performance comparison between the proposed predictive controller for the PMSG and the other classic control schemes revealed and confirmed the superiority of the designed controller in enhancing the generator dynamics.

- An effective energy management system is used to achieve a smooth power flow between the HRES units.

- The validation of the HRES is confirmed considering variable wind speed, variable solar irradiation, and variable load as well.

The present study is structured as: in Sec. 2, the modeling procedures of all system units are presented and described in detail. In Sec. 3, the control design for the separate system units is accomplished. Sec. 4 presents and describes the energy management strategy (EMS), which is used to manage the power flow between the system units. In Sec. 5, the test results are presented and described in detail. Finally, Sec. 6 presents the conclusion of the study.

\section{Modeling of System Units}

In this study, the HRES is illustrated in Fig. 1. It comprises the wind turbine/PMSG generation system, the battery storage system, the PV solar system, and the variable load. In addition, the system

Mahmoud A. Mossa (Performance Enhancement of a Hybrid Renewable Energy System Accompanied with Energy Storage Unit Using Effective Control System) 
contains the control units for each system component. The control systems contain the wind turbine power management system, the PMSG control system, the battery charging/discharging control system, and the control of the DC/DC converter of the PV panel. Consequently, to maintain the appropriate operation of the HRES, all system components must be precisely modeled and configured for each customized task.

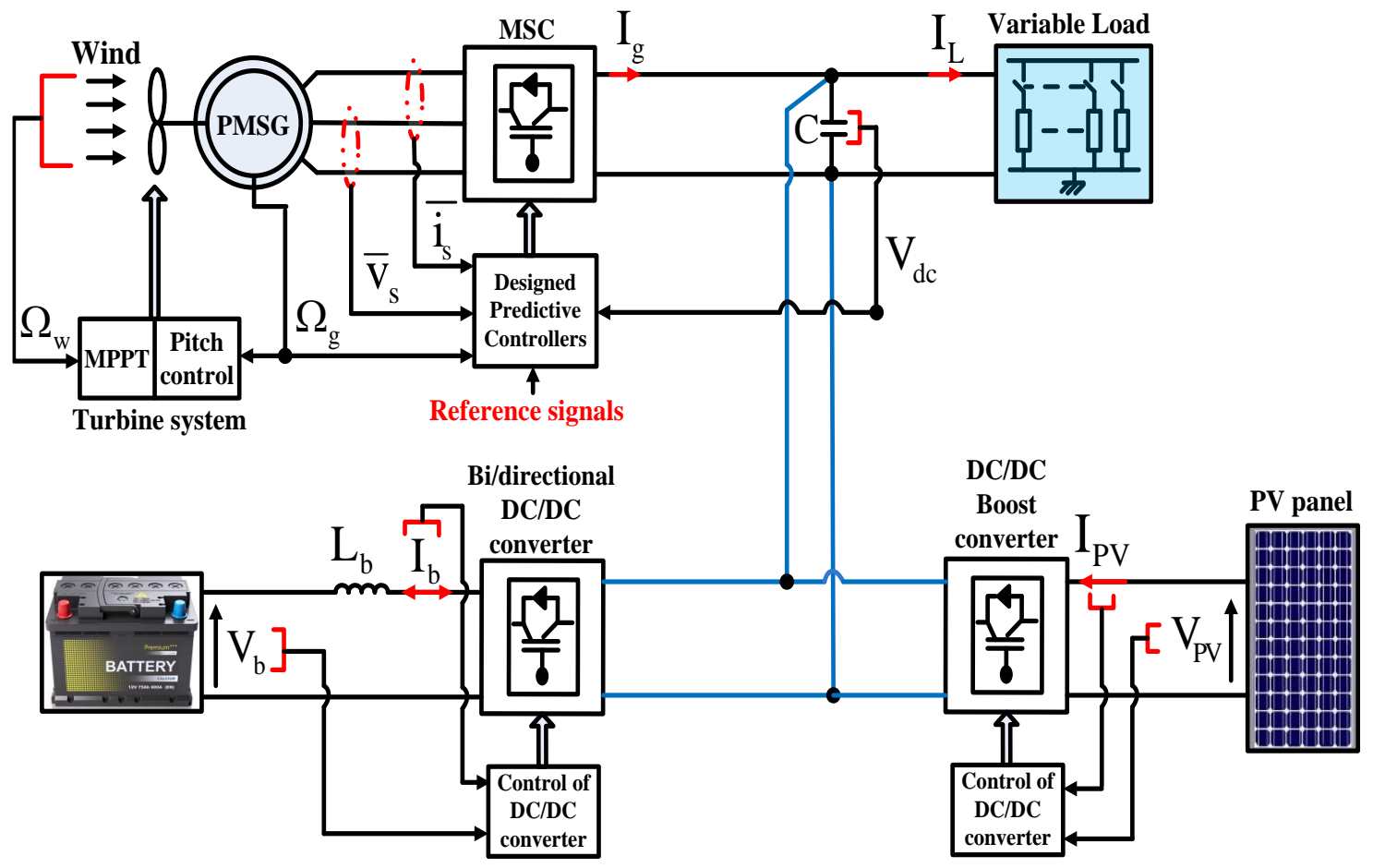

Fig. 1. The layout of HRES for standalone operation

\subsection{Modeling of a Wind Generation System}

The wind turbine system needs to be mathematically modeled to emulate the turbine aerodynamics. The system should incorporate the MPPT and pitch angle control (PAC). Generally, the MPPT is applied to achieve maximum wind power extraction when the wind speed $\left(\Omega_{w}\right)$ is lower than the nominal value; and this is accomplished via imposing the optimal tip speed ratio $\left(\lambda_{\text {opt }}\right)$ [41][42]. Alternatively, the PAC control is utilized to limit the turbine power when the speed overlaps the nominal value. The PAC control is performed by monitoring the wind speed and selecting a corresponding blade angle $(\beta)$ for each wind speed using the $V_{w}-\beta$ characteristic profile. The tip ratio $\lambda$ can be expressed by

$$
\lambda=\frac{r \Omega_{\mathrm{t}}}{\Omega_{w}}
$$

where $r$ is the blade radius.

Using $\lambda$ and $\beta$, the turbine power coefficient $C_{P}$ can be calculated by [43]

$$
C_{P}(\lambda, \beta)=0.53\left[\frac{151}{\lambda_{i}}-058 \beta-0.002 \beta^{2.14}-13.2\right] e^{\left(\frac{-18.4}{\lambda_{i}}\right)}
$$

Where $\lambda_{\mathrm{i}}=\frac{1}{\frac{1}{\lambda-0.02 \beta}-\frac{0.003}{\beta^{3}+1}}$

The relationship between $C_{P}$ and $\lambda$ for different values of $\beta$ is viewed in Fig. 2, from which it can be observed that there is an optimal $\lambda_{\text {opt }}$ which achieves maximum $C_{P, \max }$ which in turns maximizes the extracted power. 


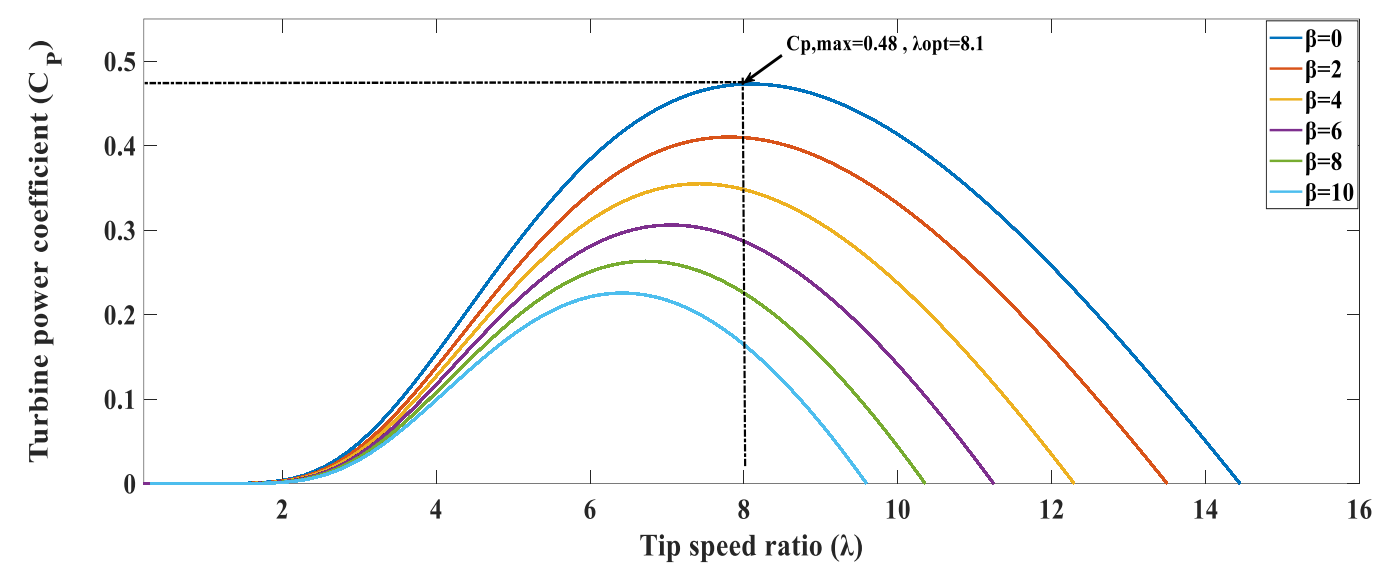

Fig. 2. Relationship between $C_{P}$ and $\lambda$ for different values of $\beta$

Then, the wind and turbine powers can be evaluated by

$$
P_{w=\frac{1}{2}} \rho A \Omega_{w}^{3}, \quad \text { and } \quad P_{t=} C_{P} P_{w}
$$

Where $A$ is the swept area, and $\rho$ is the air density.

Using (1), (2) and (3), the torque of the turbine can be evaluated by

$$
T_{t}=\frac{P_{t}}{\Omega_{\mathrm{t}}}=\frac{C_{P \cdot \frac{1}{2}} \rho A \Omega_{w}^{3}}{\Omega_{\mathrm{t}}}
$$

The torque and speed of the generator can be calculated respectively by

$$
\begin{gathered}
T_{g}=\frac{T_{t}}{G} \\
\Omega_{g=} G \Omega_{\mathrm{t}}
\end{gathered}
$$

where $G$ is the gearbox ratio.

The coupling mechanical shaft dynamics can be expressed by:

$$
T_{t}-G T_{g}-F G \Omega_{\mathrm{t}}=\left(\frac{J_{t}}{G}+G J_{g}\right) \frac{d \Omega_{\mathrm{t}}}{d t}
$$

As shown in Fig. 2, to maintain the MPPT mode, the turbine must run at optimum $\left(\lambda_{\text {opt }}\right)$, which maximizes the power coefficient $C_{P, \max }$ and the power $P_{t, \max }$ considering (2) and (3).

Consequently, the reference speeds of turbine and generator can be calculated by

$$
\begin{gathered}
\Omega_{t}^{*}=\frac{\lambda_{o p t} \Omega_{w}}{r} \\
\Omega_{g}^{*}=G \Omega_{t}^{*}
\end{gathered}
$$

\subsection{Equivalent Model of PMSG}

The mathematical model of PMSG can be formulated exploiting the following differential equations defined at instant $K T_{S}$ [35-37],

$$
\begin{gathered}
\frac{d i_{d s, k}}{d t}=\frac{1}{L_{s}}\left(V_{d s, k}-R i_{d s, k}+\Omega_{s, k} L_{s} i_{q s, k}\right) \\
\frac{d i_{q s, k}}{d t}=\frac{1}{L_{s}}\left(V_{q s, k}-R i_{q s, k}-\Omega_{s, k} L_{s} i_{d s, k}-\Omega_{s, k} \psi_{f, k}\right)
\end{gathered}
$$


The dynamics of the mechanical generator subsystem can be represented by

$$
\frac{d \Omega_{g, k}}{d t}=\frac{1}{J}\left(T_{t, k}-T_{g, k}-T_{f, k}\right)
$$

The generator torque can be evaluated by

$$
T_{g, k}=1.5 p \psi_{f, k} i_{q s, k}
$$

The parameters of the wind generation system are presented in Table A.1 in Appendix A.

\subsection{Modeling of PV System}

A solar cell is a device that uses the photovoltaic effect to convert the sunlight energy directly into electricity. The photovoltaic effect is visible in semiconductors with a P-N junction. The PV cell model is based on the static behavior of a standard P-N junction diode. Fig. 3 depicts the circuit model of a PV cell. A direct current source $I_{p h}$ is connected in parallel with a diode $D$ and shunt resistance $R_{p}$, and in series with a resistance $R_{s e}$ [44][45][46].

A typical PV array is made up of $N_{p}$ parallel PV strings with $N_{s}$ PV cells are connected in series on each string. To provide the requisite voltages and currents, a series-parallel combination of solar cells and panels is used. Fig. 3(b) depicts the circuit model of a PV array.

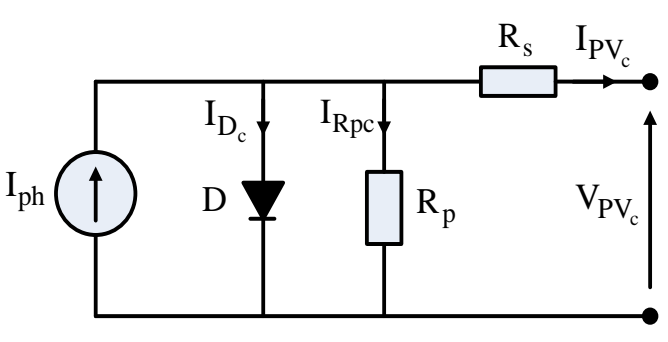

(a)

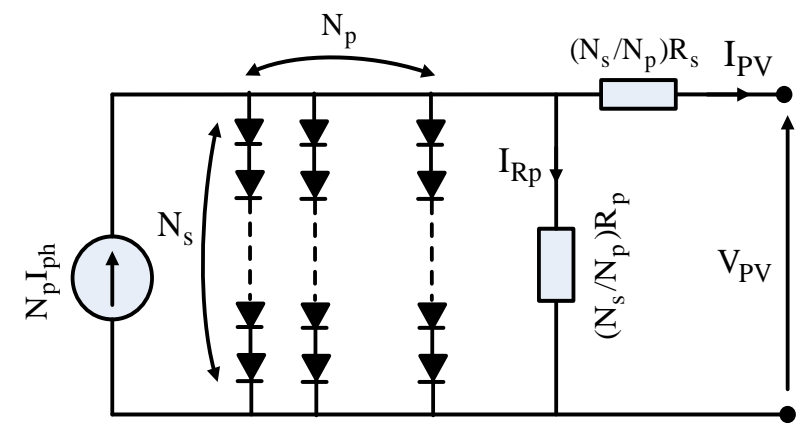

(b)

Fig. 3. (a) PV cell circuit model. (b) PV array circuit model

The output cell current $I_{P V_{C}}$ can be calculated at instant $\mathrm{KT}_{\mathrm{s}}$ by [46]

$$
I_{P V_{c}, k}=I_{p h, k}-I_{D_{c}, k}-I_{R_{p}, k}=I_{p h, k}-I_{o, k}\left[\exp \left(q \cdot \frac{V_{P V_{c}, k}+R_{S} I_{P V_{c}, k}}{f B T}\right)-1\right]-\frac{V_{P V_{c}, k}+R_{S} I_{P V_{c}, k}}{R_{p}}
$$

where $V_{P V_{C}}$ is the cell output voltage, $I_{o}$ is the diode reverse saturation current, $q$ is the electron charge, $f$ is the diode ideality factor, $T$ is the cell temperature in Kelvin $(\mathrm{K})$, and $B$ is the Boltzman's constant.

The current $I_{p h}$ changes linearly with the cell temperature $T$ and proportionally to the irradiation $S_{r}$ as follows

$$
I_{p h, k}=\left[I_{s c, k}+T_{i}(\mathrm{~T}-298) \cdot \frac{S_{r}}{1000}\right]
$$

where $I_{s c}$ is the cell short circuit current, $S_{r}$ is the irradiation $\left(\mathrm{W} / \mathrm{m}^{2}\right)$ and $T_{i}$ is the temperature coefficient $(\mathrm{A} / \mathrm{K})$.

By connecting the PV cells in a composite of series-parallel connections, the PV array is constructed with output current $I_{P V}$ calculated by

$$
I_{P V, k}=N_{p} \cdot I_{p h, k}-N_{p} I_{O, k}\left[\exp \left(q \cdot \frac{V_{P V, k}+\frac{N_{S}}{N_{p}} R_{S} I_{P V, k}}{N_{p} N_{S} F B T}\right)-1\right]-\frac{V_{P V, k}+\frac{N_{S}}{N_{p}} R_{S} I_{P V, k}}{\frac{N_{S}}{N_{p}} R_{p}}
$$

The PV array developed power $P_{P V}$ can be then expressed by 


$$
P_{P V, k}=V_{P V, k} \cdot I_{P V, k}
$$

Fig. 4 illustrates the current-voltage and power-voltage characteristics of a PV array for various levels of irradiation and constant module temperature. It is possible to state that the array power array is a non-linear function of the operating voltage, with a maximum power point (MPP). Based on these characteristics, it is possible to conclude that the voltage and power of the PV array decrease as the level of irradiation decreases.
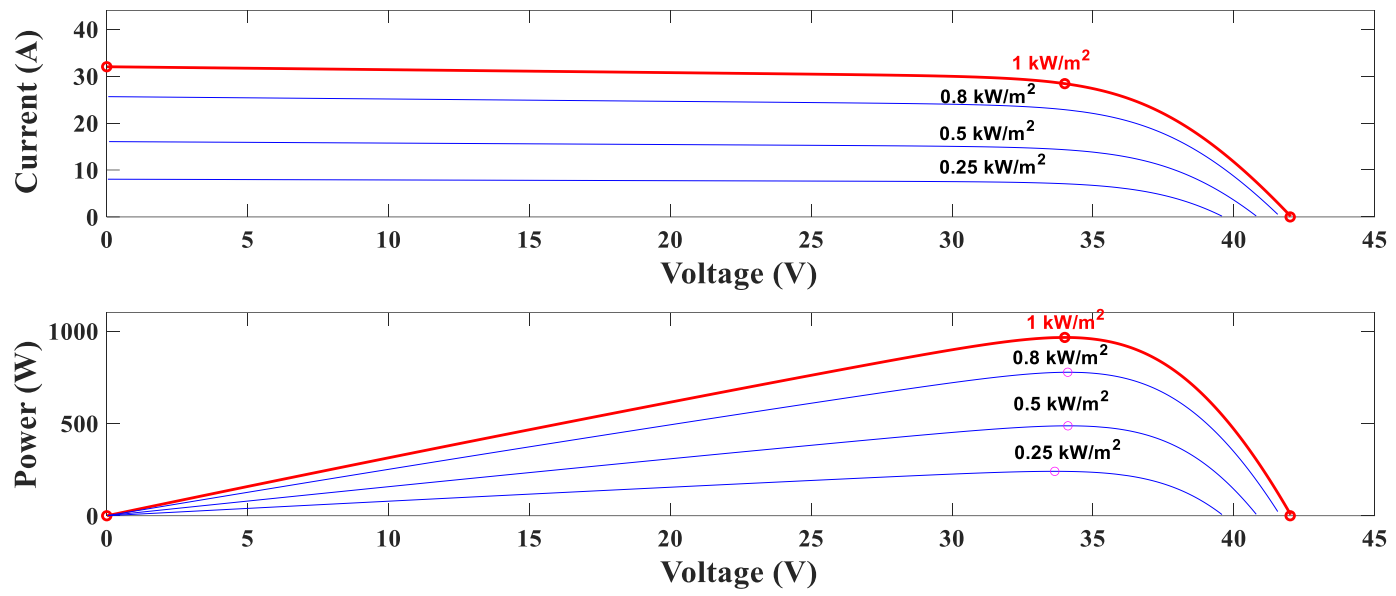

Fig. 4. Current-voltage and power-voltage characteristics of a PV array for constant module temperature and variable irradiation levels

\subsection{Modeling of Battery Storage System}

Because of the intermittent behavior of the wind and the effects of weather on the sun radiations, a battery storage system is mandatory to compensate for the power shortages under extreme weather conditions. For this reason, the battery circuit model is constructed as shown in Fig. 5. In which $V_{b}$ and $I_{b}$ refer to the battery voltage and current; $I_{b u}$ and $I_{s u}$ are the bulk and surface currents; $V_{b u}$ and $V_{s u}$ are the bulk and surface voltages; $R_{t}, R_{e}$ and $R_{s u}$ are the terminal, end and surface resistances and $C_{b u}$ and $C_{s u}$ are the bulk and surface capacitances.

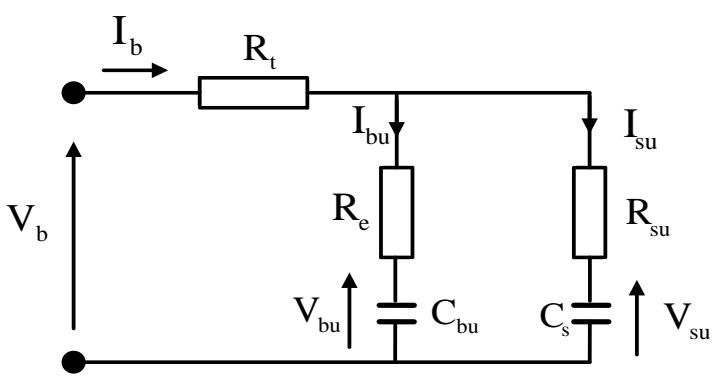

Fig. 5. Battery circuit model

Using Fig. 5, the battery voltage-current relations can be expressed by

$$
V_{b, k}=I_{b, k} R_{t}+I_{b u, k} R_{e}+V_{b u, k}=I_{b, k} R_{t}+I_{s u, k} R_{s u}+V_{s u, k}
$$

The dynamics of battery voltage can be represented in a state representation as in [47] by

$$
\left[\begin{array}{c}
\frac{d V_{b u, k}}{d t} \\
\frac{d V_{s u, k}}{d t} \\
\frac{d V_{b, k}}{d t}
\end{array}\right]=\left[\begin{array}{lll}
\gamma_{11} & \gamma_{12} & \gamma_{13} \\
\gamma_{21} & \gamma_{22} & \gamma_{23} \\
\gamma_{31} & \gamma_{32} & \gamma_{33}
\end{array}\right] \cdot\left[\begin{array}{c}
V_{b u, k} \\
V_{s u, k} \\
V_{b, k}
\end{array}\right]+\left[\begin{array}{c}
\frac{R_{s u}}{C_{b u}\left(R_{e}+R_{s u}\right)} \\
\frac{R_{e}}{C_{s u}\left(R_{e}+R_{s u}\right)} \\
Z
\end{array}\right] \cdot I_{b, k}
$$


Where $_{11}=\frac{-1}{C_{b u}\left(\mathrm{R}_{\mathrm{e}}+R_{s u}\right)}, \quad \gamma_{12}=\frac{1}{C_{b u}\left(\mathrm{R}_{\mathrm{e}}+R_{s u}\right)}, \quad \mathrm{\gamma}_{13}=0$.

$\gamma_{21}=\frac{1}{C_{s u}\left(\mathrm{R}_{\mathrm{e}}+R_{s u}\right)}, \quad \gamma_{22}=\frac{-1}{C_{s u}\left(\mathrm{R}_{\mathrm{e}}+R_{s u}\right)}, \quad \gamma_{23}=0$.

$\gamma_{31}=\frac{-R_{s u}}{C_{b u}\left(\mathrm{R}_{\mathrm{e}}+R_{s u}\right)^{2}}+\frac{\mathrm{R}_{\mathrm{e}}}{C_{s u}\left(\mathrm{R}_{\mathrm{e}}+R_{s u}\right)^{2}}-\frac{\mathrm{R}_{s u}^{2}}{C_{b u} \mathrm{R}_{\mathrm{e}}\left(\mathrm{R}_{\mathrm{e}}+R_{s u}\right)^{2}}+\frac{R_{s u}}{C_{s u}\left(\mathrm{R}_{\mathrm{e}}+R_{s u}\right)^{2}}, \quad \gamma_{32}=0$,

$\gamma_{33}=\frac{R_{s u}}{C_{b u} \mathrm{R}_{\mathrm{e}}\left(\mathrm{R}_{\mathrm{e}}+R_{s u}\right)}-\frac{1}{C_{s u}\left(\mathrm{R}_{\mathrm{e}}+R_{s u}\right)}$.

$\mathrm{Z}=\frac{\mathrm{R}_{\mathrm{e}}^{2}}{C_{b u}\left(\mathrm{R}_{\mathrm{e}}+R_{s u}\right)^{2}}-\frac{R_{s u} \mathrm{R}_{\mathrm{t}}}{C_{b u}\left(\mathrm{R}_{\mathrm{e}}+R_{s u}\right)}+\frac{R_{s u} \mathrm{R}_{\mathrm{e}}}{C_{s u}\left(\mathrm{R}_{\mathrm{e}}+R_{s u}\right)^{2}}+\frac{\mathrm{R}_{\mathrm{t}}}{C_{s u}\left(\mathrm{R}_{\mathrm{e}}+R_{s u}\right)}$.

The battery state of charge (SOC) can be evaluated using the following expression

$$
S O C_{k}=S O C_{o, k}-\frac{1}{Q_{r}} \int_{0}^{t} \mathrm{I}_{\mathrm{b}, \mathrm{k}} d t
$$

The utilized battery model in the current study is a $240 \mathrm{~V}$ with an efficiency of $\eta_{b}$ of $85 \%$, and depth of discharge $(D O D)$ bound of $60 \%$. Furthermore, the rated battery capacity is $50 \mathrm{Ah}$.

\section{Design of Control Schemes for the HRES Units}

\subsection{Control Schemes for PMSG}

As mentioned earlier, the control of wind-driven PMSG is carried out through the machine-side converter (MSC). Three controllers formulated based on the predictive control theory are used to evaluate the dynamics of PMSG and identify the most effective amongst. The three controllers are the MP DPC, MP DTC, and a newly formulated predictive control scheme. The description of each control system is presented in the following subsections.

\subsubsection{MP DPC Approach}

The MP DPC control principle is articulated by using a cost function that incorporates the absolute errors of active and reactive powers of PMSG [37]. The errors are obtained by subtracting the predicted values of powers from their relevant reference signals. After that, the resultant errors are normalized by dividing the apparent nominal power of the machine. In addition, the cost function of the MP DPC uses a weighting coefficient $w_{c}=\frac{P_{g, r a t}}{Q_{g, \text { rat }}}$ to equalize the importance of each controlled term is relevant to the other (i.e., the controlled terms are of not similar nature). The reference voltage signals are obtained by minimizing this cost function. Accordingly, the MP DPC cost function can be formulated by

$$
\Lambda_{k+1}^{i}=\left|P_{g, k+1}^{*}-\tilde{P}_{g, k+1}\right|^{i}+w_{c}\left|Q_{g, k+1}^{*}-\tilde{Q}_{g, k+1}\right|^{i}
$$

The active power reference $\left(P_{g, k+1}^{*}=T_{g, k+1}^{*} * \Omega_{g, k+1}^{*}\right)$ is calculated via multiplying the generator's torque and speed reference signals, which are derived from the wind turbine power control system described in Sec. 2. A. Alternatively, the reactive power reference $Q_{g, k+1}^{*}$ is kept at zero. Furthermore, the predicted power signals $\tilde{P}_{g, k+1}$ and $\tilde{Q}_{g, k+1}$ are evaluated by

$$
\begin{gathered}
\tilde{P}_{g, k+1}=1.5\left(V_{d s, k+1} \tilde{l}_{d s, k+1}+V_{q s, k+1} \tilde{l}_{q s, k+1}\right) \\
\tilde{Q}_{g, k+1}=1.5\left(V_{q s, k+1} \tilde{\iota}_{d s, k+1}-V_{d s, k+1} \tilde{l}_{q s, k+1}\right)
\end{gathered}
$$

where $\tilde{l}_{d s, k+1}$ and $\tilde{l}_{q s, k+1}$ are the $d-q$ current components calculated at an instant $(K+1) T_{s}$. These components can be calculated starting from (10) and (11) by

$$
\tilde{\imath}_{d s, k+1}=i_{d s, k}+\left(\frac{d i_{d s, k}}{d t}\right) T_{s} \quad \text {, and } \tilde{\imath}_{q s, k+1}=i_{q s, k}+\left(\frac{d i_{q s, k}}{d t}\right) T_{s}
$$


The predicted $d-q$ voltage components $V_{d s, k+1}$ and $V_{q s, k+1}$ can be calculated by

$$
V_{d s, k+1}=V_{d s, k}+\left(\frac{V_{d s, k-} V_{d s, k-1}}{\Delta T}\right) T_{s}, \text { and } V_{q s, k+1}=V_{q s, k}+\left(\frac{V_{q s, k-} V_{q s, k-1}}{\Delta T}\right) T_{s}
$$

The MP DPC system layout used for managing the operation of PMSG is then structured in Fig. 6. In this figure, the MD DPC system starts its operation by measuring and sampling the stator voltage $\bar{V}_{S}$ and stator current $\bar{l}_{S}$ and use them besides the generator speed $\Omega_{g}$ to predict the active and reactive powers $\left(\widetilde{P}_{g, k+1}\right.$ and $\left.\tilde{Q}_{g, k+1}\right)$. The control system also generates the active reference power $P_{g, k+1}^{*}$ and use it besides the reactive power reference $Q_{g, k+1}^{*}=0$ as inputs to the cost function block. The cost function blocks are then used as a tool to generate the optimal switching states for the MSC.

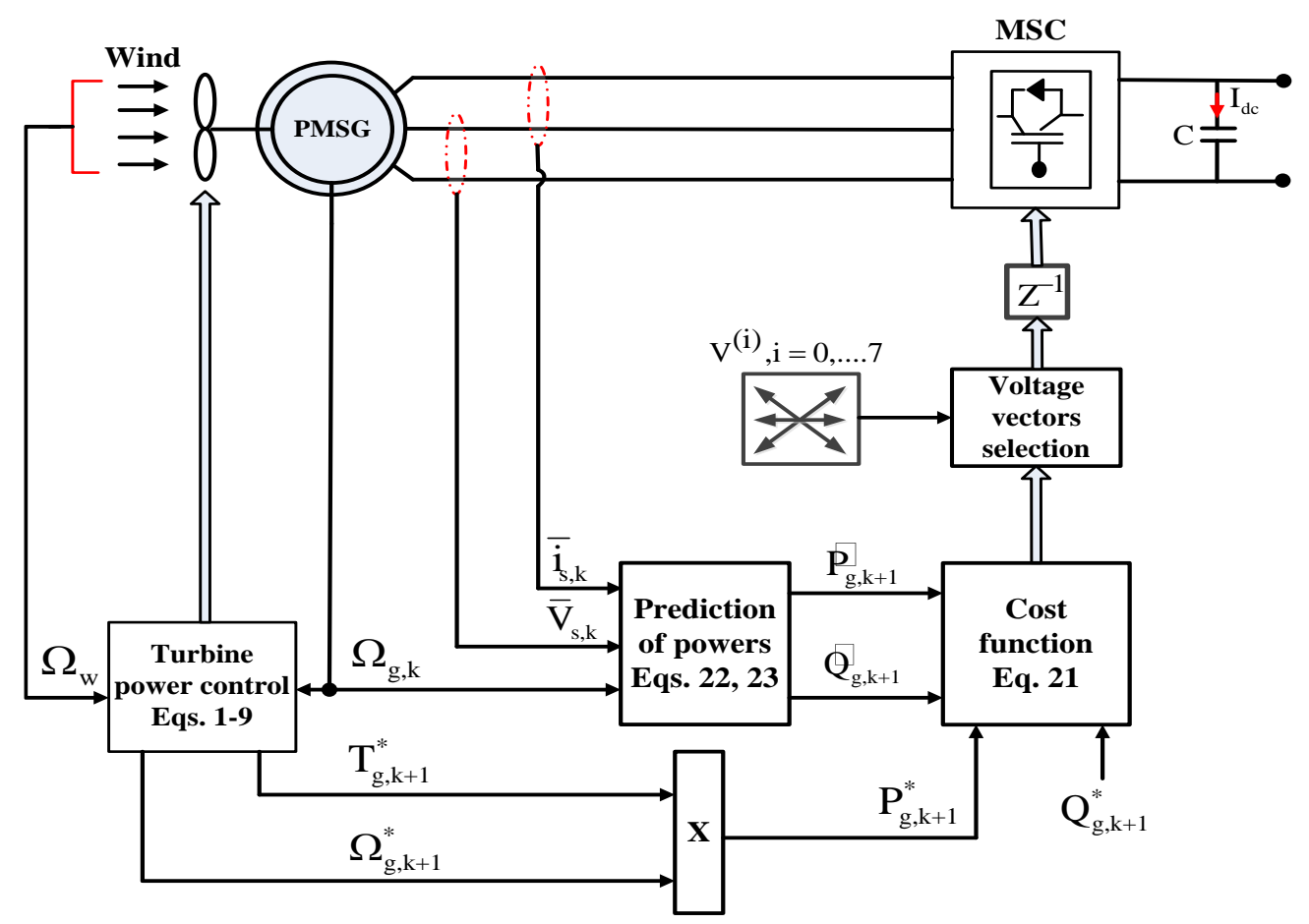

Fig. 6. The layout of the MP DPC control scheme for PMSG

\subsubsection{MP DTC Approach}

The generator torque and flux are the controlled variables considered by the MP DTC approach [38]. Consequently, the cost function used by the MP DTC consists of the normalized torque and flux errors along with a weighting coefficient $w_{c}^{\prime}=\frac{T_{g, \text { rat }}}{\psi_{g \text {,rat }}}$. The operation of this cost function is an alternative to the hysteresis-based controllers used besides the look-up tables in traditional DTC control. Accordingly, the MP DTC cost function, which provides the reference voltage vectors, can be represented by

$$
\Lambda_{k+1}^{i}=\left|T_{g, k+1}^{*}-\widetilde{T}_{g, k+1}\right|^{i}+w_{c}^{\prime}\left|\psi_{g, k+1}^{*}-\tilde{\psi}_{g, k+1}\right|^{i}
$$

where $T_{g, k+1}^{*}$ and $\psi_{g, k+1}^{*}$ are the command signals of generator torque and flux.

The torque reference $T_{g, k+1}^{*}$ is extracted from the wind turbine power system described previously (Eq. 1-9); while the flux reference $\psi_{g, k+1}^{*}$ is calculated as follows

$$
\psi_{g, k+1}^{*}=\sqrt{\left(L_{s} i_{d s, k+1}^{*}+\psi_{f, k+1}\right)^{2}+\left(L_{s} i_{q s, k+1}^{*}\right)^{2}}
$$


The reference currents are identified by as following

$$
i_{d s, k+1}^{*}=0 \quad \text {, and } \quad i_{q s, k+1}^{*}=\frac{T_{g, k+1}^{*}}{1.5 p \psi_{f, k+1}}
$$

In addition, $\tilde{T}_{g, k+1}$ and $\tilde{\psi}_{g, k+1}$ are the predicted values of the torque and flux.

Alternatively, the predicted quantities of torque and flux are calculated by

$$
\begin{gathered}
\tilde{T}_{g, k+1}=1.5 p \psi_{f, k+1} \tilde{l}_{q s, k+1} \\
\tilde{\psi}_{g, k+1}=\sqrt{\left(L_{s} \tilde{l}_{d s, k+1}+\psi_{f, k+1}\right)^{2}+\left(L_{s} \tilde{l}_{q s, k+1}\right)^{2}}
\end{gathered}
$$

The currents $\tilde{\imath}_{d s, k+1}$ and $\tilde{l}_{q s, k+1}$ are obtained using (24).

As the MP DTC control adopts the FCS principle for selecting the voltage vectors, then the MP DTC begins to calculate (26) using the possible eight voltages and then identifies the primary vector, which keeps the cost function at its minimum value and finally implement it to the windings. The control system structure of the MP DTC is then constructed using the presented formulas as shown in Fig 7. The MD DTC system starts its operation by measuring and sampling the stator voltage $\bar{V}_{s}$ and stator current $\bar{l}_{s}$ and use them in addition to the speed $\Omega_{g}$ to predict the torque and flux powers $\left(\widetilde{T}_{g, k+1}\right.$ and $\left.\tilde{\psi}_{g, k+1}\right)$. The control system calculates the reference stator flux $\psi_{g, k+1}^{*}$ and use it besides the reference torque $T_{g, k+1}^{*}=0$ as inputs to the cost function block, which provides at the last stage the switching signals of the MSC.

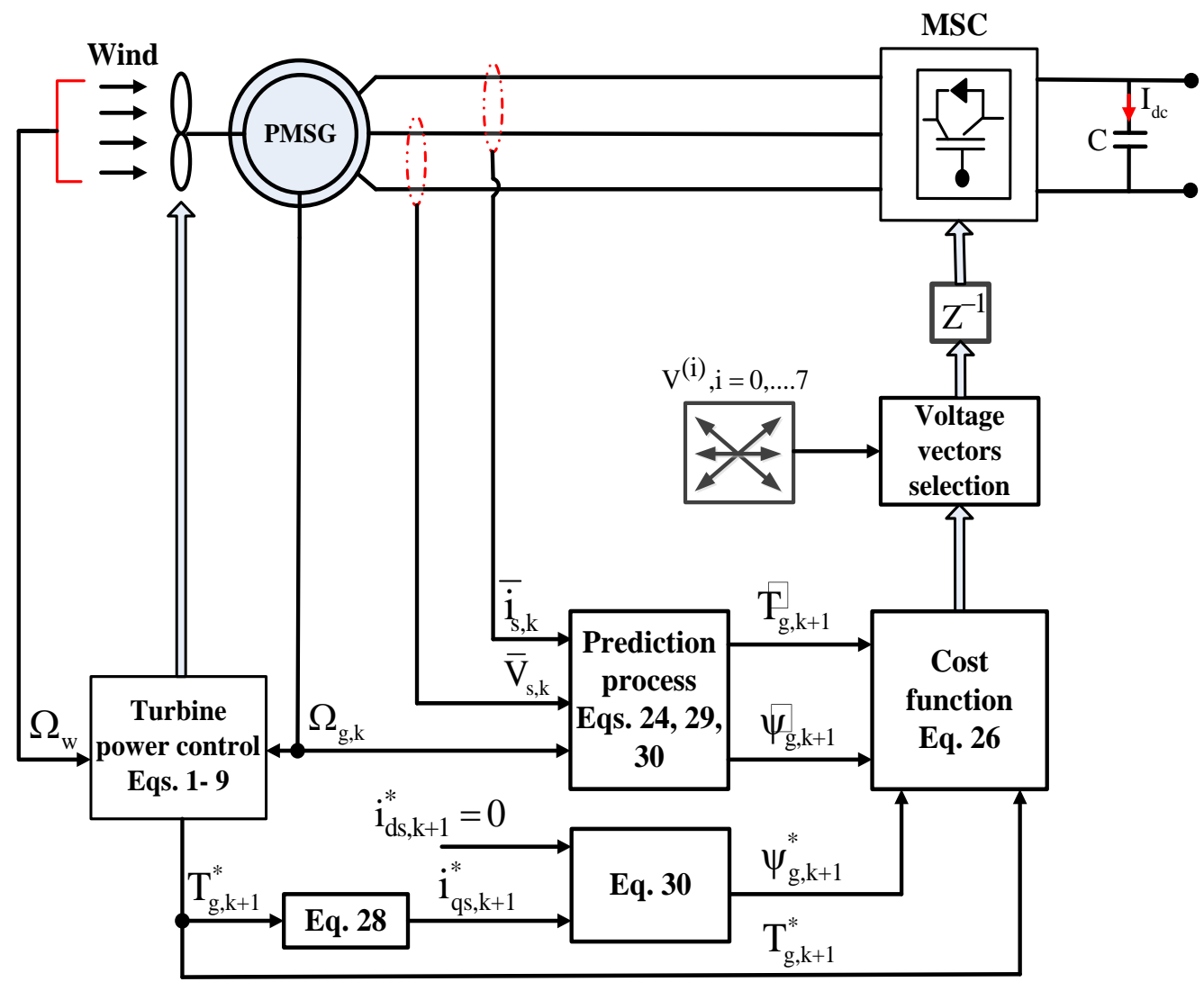

Fig. 7. The layout of the MP DTC control scheme for PMSG

\subsubsection{The Proposed Predictive Control Approach}

The proposed predictive control scheme is formulated to overcome the shortages in the MP DPC and MP DTC schemes. The designed approach utilizes a cost function that consists of two terms with 
the same nature to avoid using a weighting coefficient which contributes to restricting the ripples that can be generated from the wrong identification of weighting value. In addition, the used cost function considers a variable that does not require high computation like the variables used in MP DPC and MP DTC approaches. This helps effectively in simplifying the control structure and provides better dynamic behavior.

The controlled variables of the cost function are the absolute errors of the $\alpha-\beta$ generator voltage components, which can be then expressed by

$$
\Lambda_{k+1}^{i}=\left|V_{\alpha s, k+1}^{*}-V_{\alpha s, k+1}\right|^{i}+\left|V_{\beta s, k+1}^{*}-V_{\beta s, k+1}\right|^{i}
$$

As shown in (31), the actual and reference voltage components are required to evaluate the cost function. The actual voltage components $V_{\alpha s, k+1}$ and $V_{\beta s, k+1}$ can be obtained with the help of the finite control set (FCS) principle [48][49]. Meanwhile, the reference voltage components are obtained in a systematic manner as follows:

Considering that the PMSG model is represented in a stationary reference frame, the reference voltage vector $V_{s}^{*}$ can be calculated in terms of the reference stator flux vector. The reference voltage vector can be determined based on the torque angle increment, the predicted stator position (electrical position), and the reference flux value. A space vector representation showing the displacements between the stator and rotor fluxes of PMSG at different sampling instants is shown in Fig. 8.

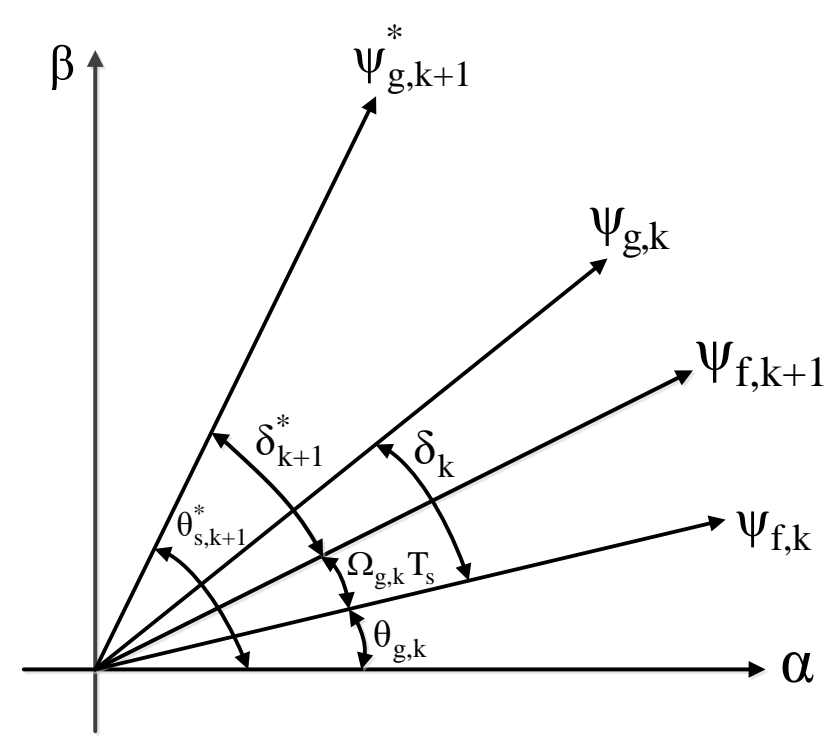

Fig. 8. State space representation of flux vectors

From Fig. 8 , the reference flux vector components can be expressed in stationary $(\alpha-\beta)$ frame by

$$
\begin{gathered}
\psi_{\alpha g, k+1}^{*}=\left|\bar{\psi}_{g, k+1}^{*}\right| \cos \left(\delta_{k+1}^{*}+\Omega_{g, k} T_{s}+\theta_{g, k}\right) \\
\psi_{\beta g, k+1}^{*}=\left|\bar{\psi}_{g, k+1}^{*}\right| \sin \left(\delta_{k+1}^{*}+\Omega_{g, k} T_{s}+\theta_{g, k}\right)
\end{gathered}
$$

The reference torque angle $\delta_{k+1}^{*}$ in (32) and (33) can be obtained using the following expression

$$
\delta_{k+1}^{*}=\sin ^{-1}\left(\frac{T_{g, k+1}^{*}}{1.5 \frac{p}{L_{s}}\left|\bar{\psi}_{g, k+1}^{*}\right| \psi_{f, k+1}}\right)
$$

Then by using (32) and (33), the reference voltage components represented in a stationary frame can be obtained by 


$$
\begin{aligned}
& V_{\alpha s, k+1}^{*}=\frac{\psi_{\alpha g, k+1}^{*}-\psi_{\alpha g, k}}{T_{s}}+R i_{\alpha s, k} \\
& V_{\beta s, k+1}^{*}=\frac{\psi_{\beta g, k+1}^{*}-\psi_{\beta g, k}}{T_{s}}+R i_{\beta s, k}
\end{aligned}
$$

Till now, the terms of the cost function (31) are obtainable, the function can be evaluated at each instant, and the control can perform its task. By checking the terms of (31) and comparing it with the terms of (21) and (26), it is realized that the designed cost function does not exhibit high computation burdens; this is in addition to the simplicity it offers due to the absence of weighting value. The overall system layout, which summarizes the previous calculation steps, is shown in Fig. 9.

In Fig. 9, the proposed control system measures the voltage $\bar{V}_{s}$ and current $\bar{l}_{s}$ at the generator terminals, then uses them besides the generator angular speed $\Omega_{g}$ to calculate the flux components $\psi_{\alpha s}$ and $\psi_{\beta s}$. The control system also calculates the reference flux amplitude $\left|\psi_{g}^{*}\right|$ using the reference $d$-q current components $\left(i_{d s}^{*}, i_{q s}^{*}\right)$ as mentioned in Eq. 35 . The reference torque signal $T_{g}^{*}$ is obtained from the turbine power control system. After that, the control system uses the reference torque and flux amplitude values to calculate the reference flux components $\left(\psi_{\alpha s}^{*}, \psi_{\beta s}^{*}\right)$ using Eqs. 32, 33 and 34. After that, the actual and reference flux components are used to calculate the stator voltage reference components $\left(V_{\alpha s}^{*}, V_{\beta S}^{*}\right)$ using Eqs. 35 and 36. Finally, the reference voltage components are used by the cost function block (governed by Eq. 31) to generate the switching states for the MSC.

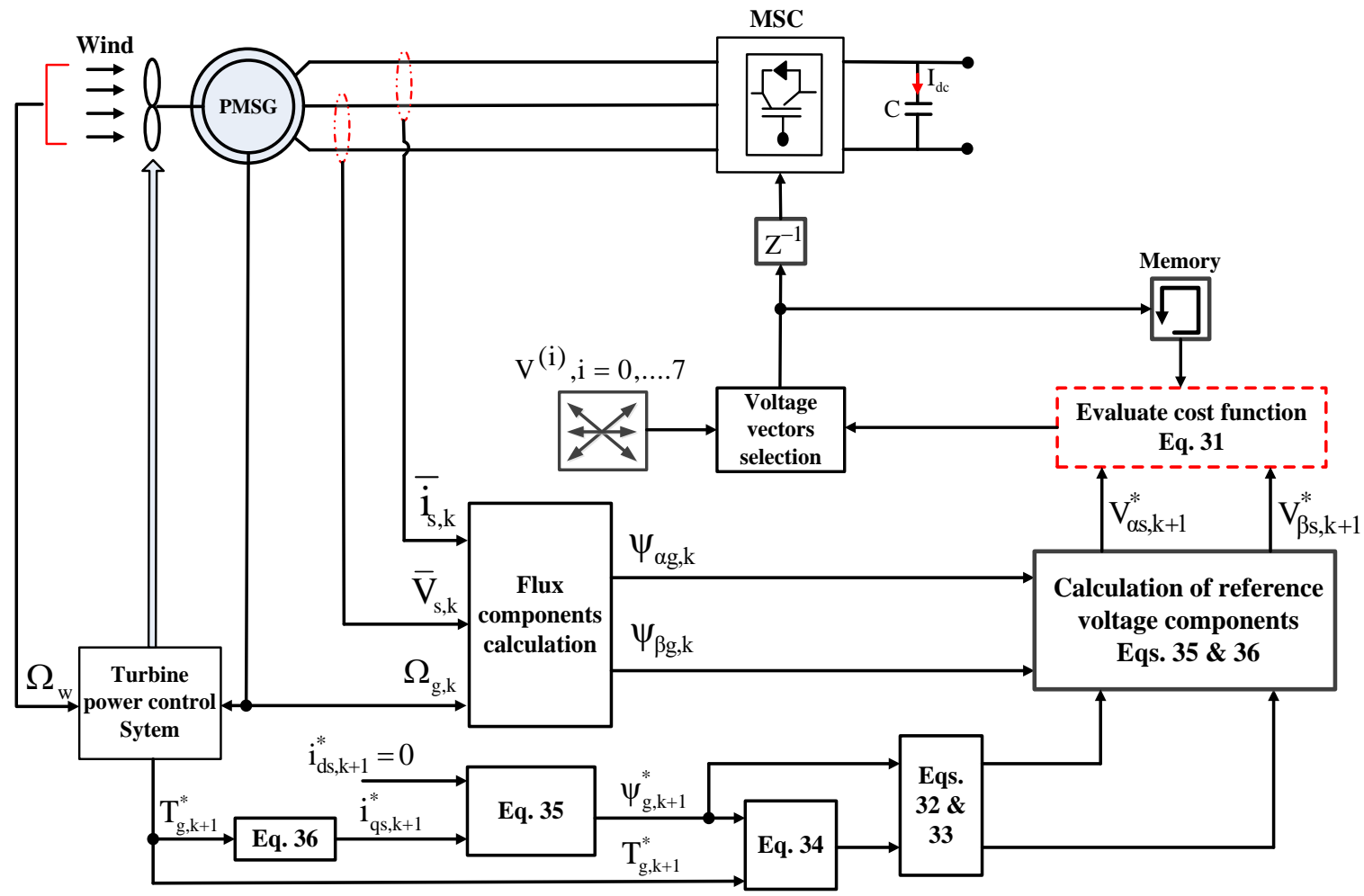

Fig. 9. Layout of proposed predictive controller for PMSG

A flow chart, which summarizes the operation steps of the proposed predictive control scheme, is illustrated in Fig. 10. 


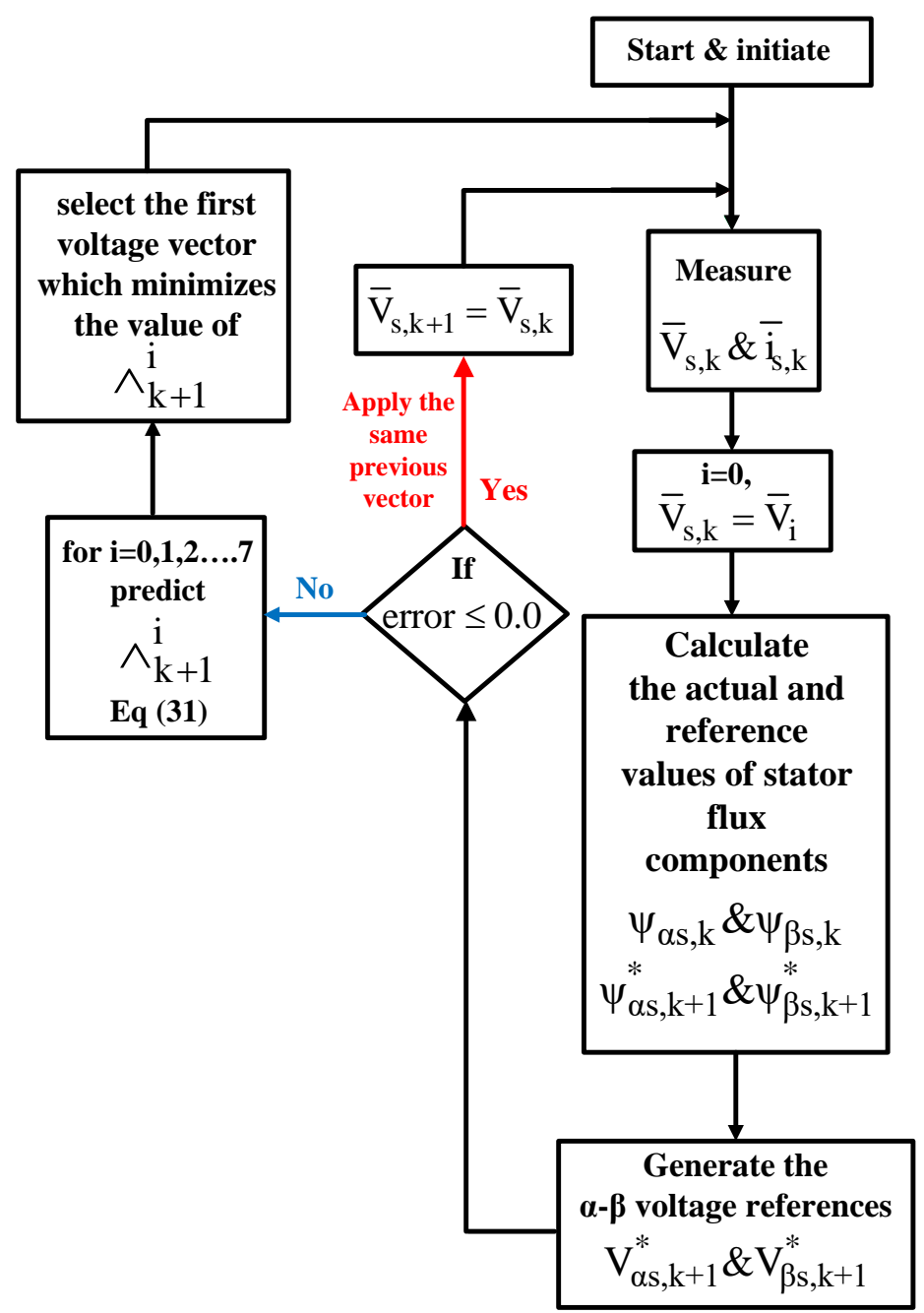

Fig. 10. Flowchart for the proposed predictive control scheme

\subsection{Control DC-DC Converter for PV Array}

The converter topology of the DC/DC Boost Converter used for converting the electrical energy obtained from the PV array is shown in Fig. 11. As illustrated, the controlled switch $S$, the diode $D_{b}$, the inductor $L_{d}$, and the capacitor $C_{d}$ constitute the DC/DC converter.

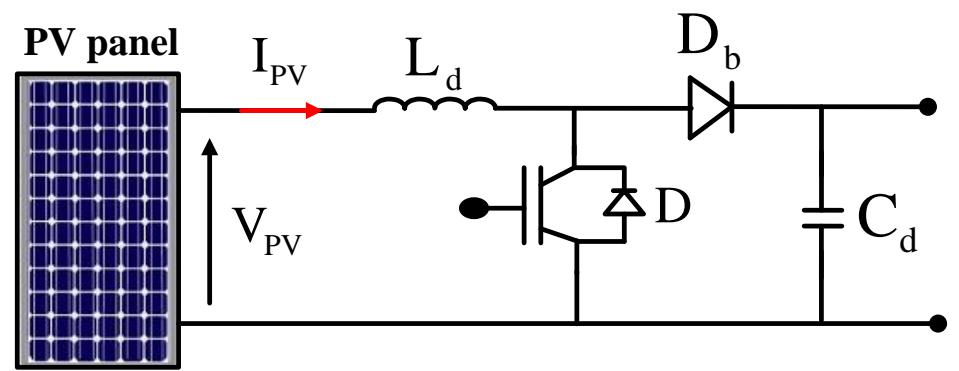

Fig. 11. DC-DC converter configuration for PV array system

The MPPT strategy is utilized for the operation control of the PV converter in order to optimize the operation and efficiency of the PV system. The Perturb and Observe (P\&O) procedure is considered in this study [50][51]. Fig. 12 illustrates the control strategy's premise in a flow chart form. 
In order to identify the highest point of output array power, the $\mathrm{P} \& \mathrm{O}$ method employs the incremental increasing/decreasing of the array voltage concept [51]. The PV array voltage is perturbed on a regular basis, and the PV output power is compared to that of the previous perturbation cycle.

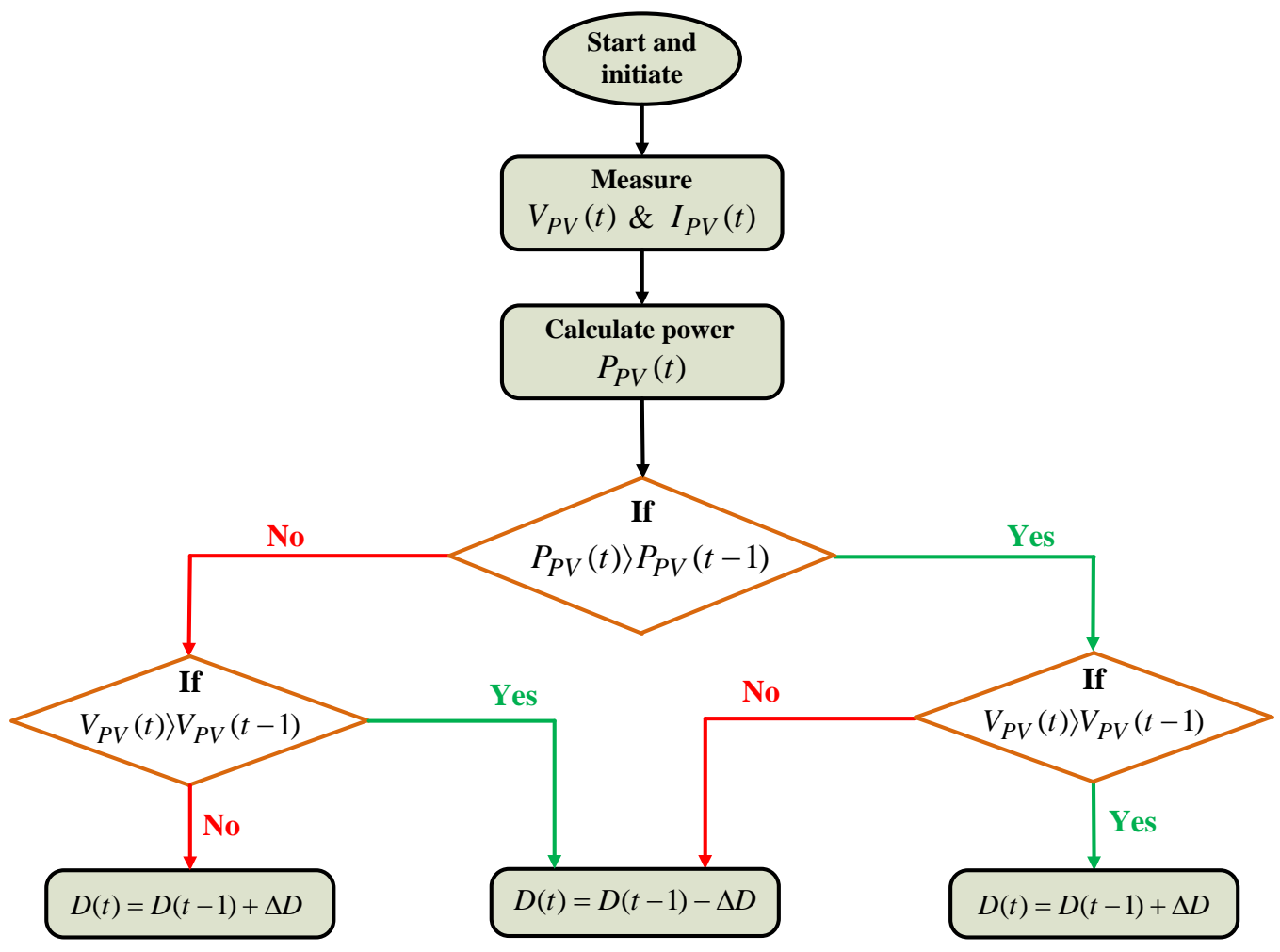

Fig. 12. Implementation sequence of $\mathrm{P} \& \mathrm{O}$ method for $\mathrm{MPPT}$

\subsection{Control of Bi-directional Battery Converter}

To manage the energy flow to/from the battery, a bidirectional DC-DC converter is used. The converter configuration is illustrated in Fig. 13.

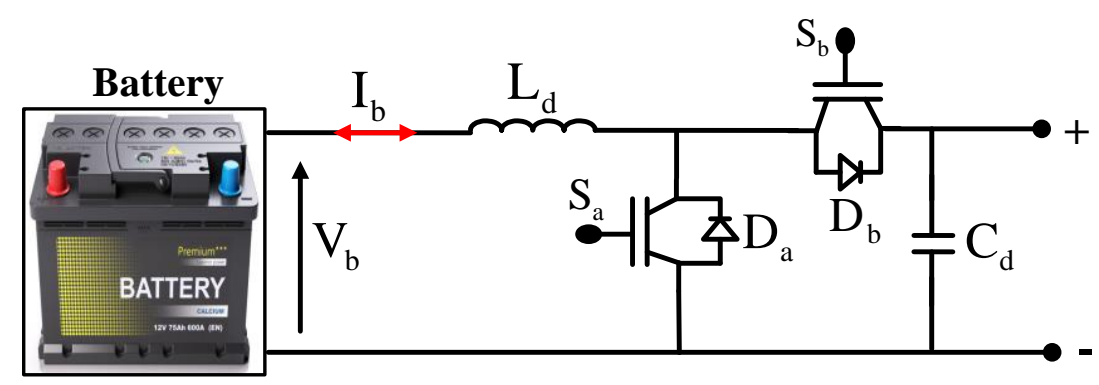

Fig. 13. Reversible current chopper for battery storage

Two regulated switches, $S_{a}$ and $S_{b}$, an inductor $L_{d}$, and a capacitor $C_{d}$ make up the DC/DC converter. The converter can be handled as a hybrid of two fundamental chopper models: the stepdown and step-up chopper models. The bidirectional DC/DC converter allows for charging the battery in the power mode and discharging the battery in regenerative mode. The control signals of the two switches $\left(S_{a}, S_{b}\right)$ are provided using a suitable control algorithm.

Fig. 14 illustrates the control scheme of the converter switches. The required battery power $P_{b}^{*}$ is calculated as the net power between the load power $P_{L}$, the wind turbine generated power $P_{g}$ and the solar generated power $P_{P V}$. The obtained reference battery power $P_{b}^{*}$ value is then divided by the battery voltage $V_{b}$ to obtain the reference battery current $I_{b}^{*}$. The reference current $I_{b}^{*}$ is then compared to the actual battery current $I_{b}$ and the difference is fed to a PI regulator which finally provides the 
reference duty cycle $D_{1}$. In order to protect the battery from the over power charging, limiters are used which help in keeping the battery power within the permissible maximum limits.

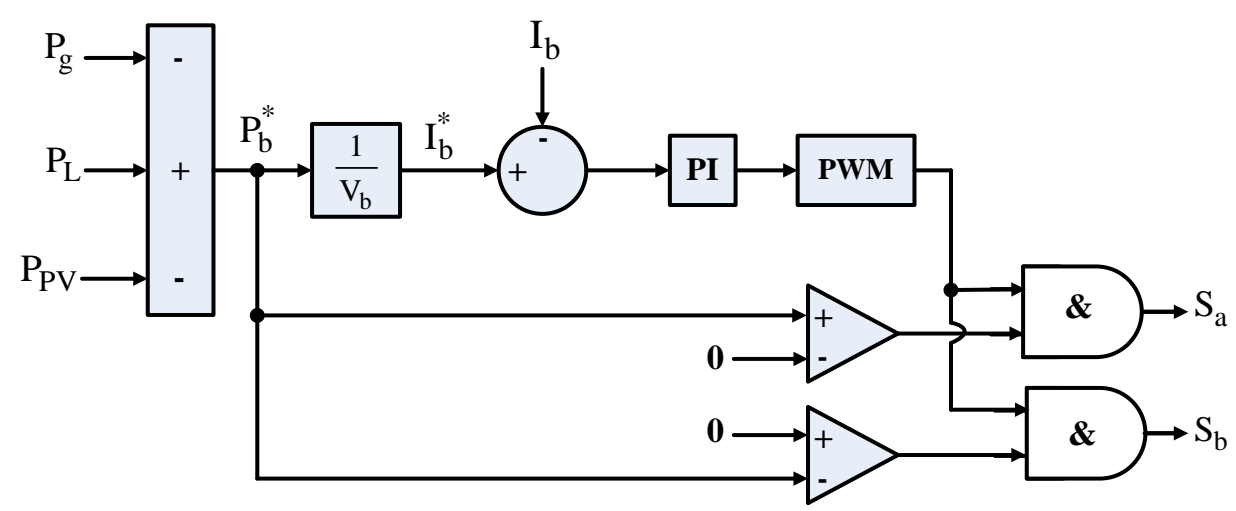

Fig. 14. Layout of control scheme used for generating switching signals

\section{Energy Management Strategy (EMS)}

Under diverse climatic conditions, the specific energy management strategy (EMS) is created to operate both the solar and wind energy systems at maximum power. As a result, the MPPT systems for wind and PV energy, battery energy storage, and load switching are all part of the EMS strategy. The state of charging (SOC) of the battery is also managed in the designed EMS in order to preserve a long battery life. The operating value of SOC is maintained among the minimum value $S O C_{\min }$ (about 20\%) and the maximum value $S O C_{\max }$ (roughly 80-90\%). Furthermore, the maximum permitted power load of the battery should not be exceeded during battery charging/discharging procedures.

Fig. 15 illustrates the power flow diagram in the HRES, there are two main generating units (PV and wind driven PMSG), one storage unit (the battery), one consuming unit (the load) and a connecting and handling unit (the DC link).

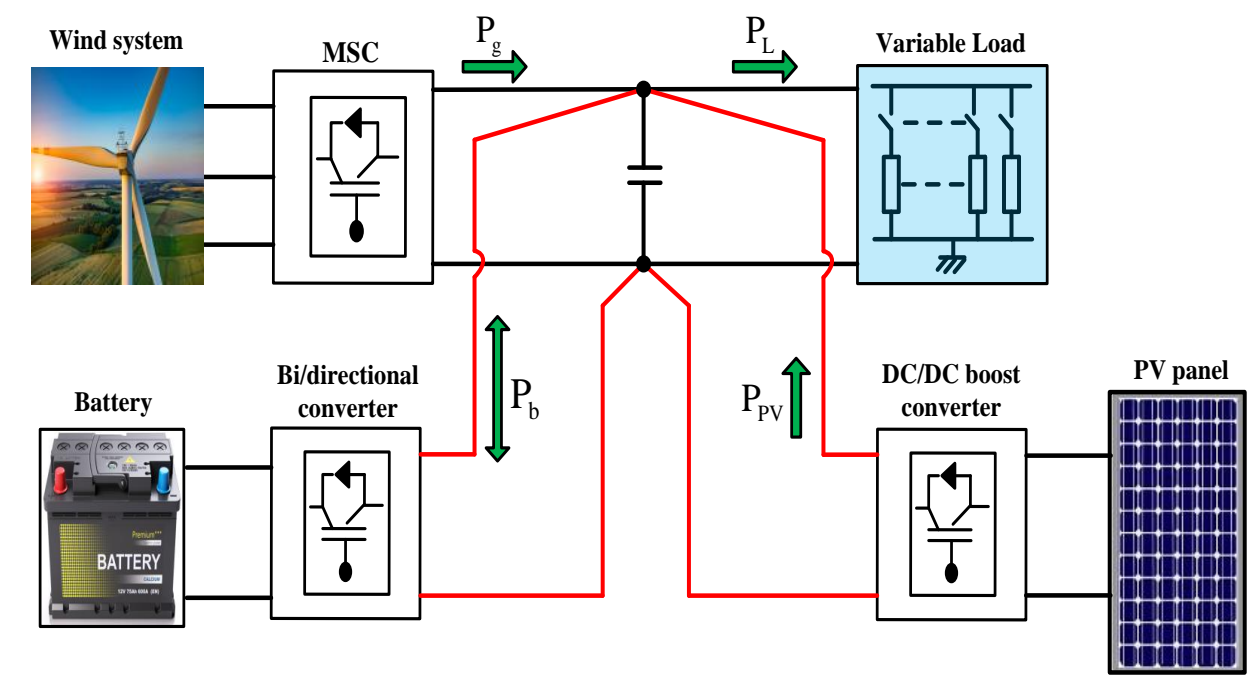

Fig. 15. Flow of power between the HRES units

The power terms can have different signs depending on whether the power is provided to or delivered from the DC link bus. Accordingly, the EMS target is to balance the power between these units. Fig. 16 configures the adopted EMS strategy, from which it is realized that when the total 
generated power generated by wind and PV systems $\left(P_{g}+P_{P V}\right)$ exceeds the load power $P_{L}$, the excess power $P_{S u r}$ will charge the battery when $P_{S u r} \leq P_{b, \max }$ is met. The battery can be charged until it reaches $100 \%$ capacity. The surplus power $P_{S u r}$ cannot be stored when the battery is fully charged or $P_{\text {Sur }}>P_{b, \max }$, hence it should be restricted. This action can be obtained by reducing the renewable energy generation by preventing control systems from operating at maximum power points or simply by turning off the selected generation sources. In this situation, excess power can be dumped in some extra energy loads that are specifically connected to the system. There will be a deficit power $P_{D e f}=$ $\left[P_{L}-\left(P_{g}+P_{P V}\right)\right]$ in the system if the total power generated $\left(P_{g}+P_{P V}\right)$ is less than the load power $P_{L}$. To compensate for the power shortage, the battery will be depleted. Because of the restricted battery capacitance, this state is only attainable for a set amount of time. The battery capacitance should be calculated for a period of no energy production or a reduction in the value of the generated energy.

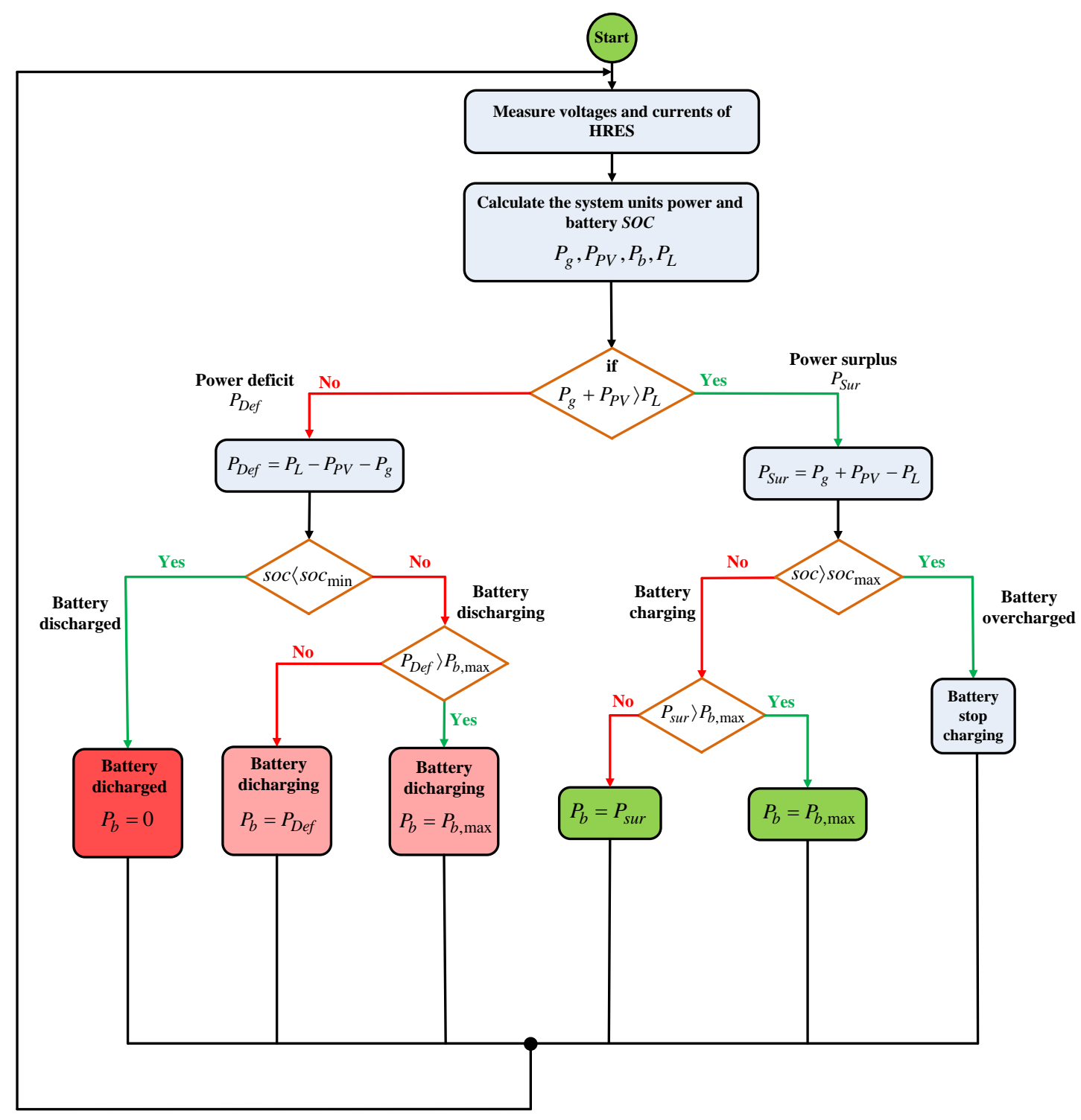

Fig. 16. Layout of EMS for the hybrid energy system

\section{Test Results}

The testing procedure for the constructed HRES is performed considering the turbine power system control (including the MPPT and blade pitch angle control), the PMSG control, the PV system 
control, and the energy management strategy (EMS). Consequently, the results are presented in a systematic manner: starting with the dynamics of the wind turbine system, following with analyzing the PMSG performance, and concluding with analyzing the EMS performance. The results are obtained considering the three predictive controllers (MP DPC, MP DTC, and proposed controller) with the PMSG and considering the MPPT algorithm with the PV generation system.

Fig. 17 illustrates the variable wind speed profile applied to the turbine blades, meanwhile Fig. 18 illustrates the generator shaft speed using the three predictive controllers, from which it is realized that the PMSG speed follows precisely the variation in the wind speed, which validates the effectiveness of the constructed wind turbine system. The actual generator speed is precisely tracking the reference speed with resultant minimum deviation, as shown in Fig. 19. The validity of the MPPT and blade pitch angle control is confirmed through Fig. 20, Fig. 21 and Fig. 22 which configures the variation of tip speed ratio $\lambda$, blade pitch angle $\beta$ and the power coefficient $C_{p}$, respectively. The value of $\lambda$ is kept to its optimal value $\left(\lambda_{o p t}=8.1\right)$ to achieve maximum power extraction. Meanwhile, the values of $\beta$ and $C_{p}$ are exhibiting an increase respectively and decrease when the wind speed overlaps its nominal value. These actions validate the adopted pitch angle control.

The dynamics of PMSG using the three predictive controllers are also investigated in order to visualize and confirm the superiority of the proposed predictive controller. Fig. 23 and Fig. 24 illustrate the active and reactive power profiles, and a detailed view of the power dynamics, respectively. From these two illustrations, it is confirmed that the designed predictive controller is providing fewer power ripples compared with the MP DPC and MP DTC approaches. This fact is also confirmed in Fig. 25 and Fig. 26, which show the generator torque dynamics and the variation of $d-q$ axis components of stator current, respectively. A detailed view of currents variation is also presented in Fig. 27, showing a ripple reduction with the values obtained with the proposed predictive controller. The two figures are also approving that the actual values of torque and currents are following their references with high performance. Furthermore, the generated currents profiles are also shown for the three controllers in respectively in Fig. 28, Fig. 29, and Fig. 30. From these figures, it is confirmed that the proposed controller provides the lowest current harmonics.

In order to perform a more detailed investigation of the performances of the three predictive controllers, the fast Fourier transform (FFT) analysis for the stator currents is performed, and the THD values are recorded in Table 1. Meanwhile, the current spectrums are shown in Fig. 31, Fig. 32, and Fig. 33. From the analytical values of currents THD and the illustrated current spectrum figures as well, it can be confirmed that the proposed predictive control scheme exhibits the lowest current harmonics, which enables providing better dynamic performance for the PMSG.

Table 1. FFT analysis of PMSG currents for the three predictive controllers

\begin{tabular}{cccc}
\hline Current phase & MP DPC (Ref. [37]) & MP DTC (Ref. [38]) & $\begin{array}{c}\text { Proposed predictive } \\
\text { control }\end{array}$ \\
\hline Phase 'a' & Fundamental (7.1593 A) & Fundamental (6.6484 A) & Fundamental (7.9334 A) \\
& THD $(11.67 \%)$ & THD $(11.57 \%)$ & THD (6.67\%) \\
Phase 'b' & Fundamental (6.6759 A) & Fundamental $(6.5507 \mathrm{~A})$ & Fundamental (8.2244 A) \\
& THD $(23.51 \%)$ & THD $(23.83 \%)$ & THD $(11.20 \%)$ \\
Phase 'c' & Fundamental (6.8424 A) & Fundamental (6.1196 A) & Fundamental (8.6601 A) \\
& THD $(24.70 \%)$ & THD $(21.40 \%)$ & THD (12.18\%) \\
\hline
\end{tabular}

The comparison between the three predictive controllers used for controlling the PMSG can also be performed in terms of the executed number of commutations. This factor is considered as a measure of the computational burden that each controller can provide. It is very recommended to maintain a low burden in order to fulfill the need for microcontrollers that handle the control process. Accordingly, the statistics are addressed in Table 2, which confirm the superiority of the proposed predictive controller over the MP DPC, and MP DTC approaches in achieving remarkable low commutations. This action helps effectively in limiting the switching losses.

Mahmoud A. Mossa (Performance Enhancement of a Hybrid Renewable Energy System Accompanied with Energy Storage Unit Using Effective Control System) 
Table 2. Number of commutations for the three predictive controllers used with PMSG

\begin{tabular}{cc}
\hline Approach & Commutations number \\
\hline MP DPC & 85100 \\
MP DTC & 82380 \\
Proposed & 11730 \\
\hline
\end{tabular}

The further test results are dedicated to approving the ability of constructed EMS in maintaining a smooth and balanced power flow between the HRES units (generating, storing, and consuming units). It is noticed that the PMSG power is following the wind variation effectively. Meanwhile, the PV generated power following appropriately the adopted irradiation variation. Fig. 34 and Fig. 35 show, respectively, the power and current flows between the system units considering the three used controllers with the PMSG. To analyze the dynamics of power flow, the procedure is bisected into seven stages which can be summarized as follows:

In stage 1, there is no load, and the PMSG generates power, and there is no power generated from the PV system. Consequently, the battery is charging.

In stage 2, the load is increased and covered by the sum of the generated powers from the wind and PV. Meanwhile, the excess power is charging the battery.

In stage 3, the load is further increased in a way that cannot be covered only by the PV and wind power. Consequently, the battery is discharging to cover the power shortage.

In stage 4, the load is decreased; the wind and PV powers are almost covering it with a slight shortage covered by the battery.

In stage 5, the load is further decreased, the PV and wind system generate sufficient powers to feed the load. Meanwhile, excess power is used to charge the battery.

In stage 6, the behavior is similar to stage 3 .

In stage 7, the load is decreased, and the generated power from the PV and wind system is much higher; consequently, to achieve the balance, the excess power is charging the battery.

The profile of the DC link is also presented in Fig. 36, which confirms the effectiveness of the designed control systems in maintaining the voltage very concisely with the reference value (400 V). From the obtained results, it is confirmed that the EMS has succeeded in achieving the power balance in the HRES; and the MPPT algorithms used with the wind turbine and PV systems approved effectively their ability to achieve optimal exploitation for the wind and solar energy, respectively. In addition, the superiority of the designed predictive controller over the MP DPC and MP DTC in controlling the PMSG dynamics is also confirmed.

\section{Conclusion}

The paper is concerned with enhancing the performance of a hybrid renewable energy system (HRES) through managing the operation of each system unit using effective control systems. In addition, an energy management strategy is used to achieve a balanced power flow between the HRES system units to enhance the system capability in covering the isolated loads under standalone operation. The HRES under study consisted of a wind generation system, a PV system, and a battery storage system. The wind generation system utilized a PMSG generator which is controlled using three different predictive control schemes: two classics (MP DPC and MP DTC) and one proposed. The test results illustrated and confirmed the superiority of the proposed predictive controller over the classic two controllers; this is observed through the reduced ripples and current harmonics and the reduced computation burden as well. The study also used two MPPT strategies with the wind and PV systems to maximize power extraction. The study proposed an energy management strategy (EMS) in order to guarantee a balanced power flow between all system units. In addition, the battery charging/discharging process is effectively managed. Consequently, it can be concluded that the 
obtained results approved and emphasized the effectiveness of the designed EMS in preserving the HRES capability in covering the variable load.

In brief, the research outputs and recommendations for future work can be itemized as follows:

- A systematic design for an HRES system is introduced and explained in detail.

- A new predictive control scheme is proposed to improve the dynamics of the PMSG used in the HRES.

- Detailed performance analysis for the wind-driven PMSG is introduced to outline the superiority of the proposed predictive control over the classic control approaches.

- An effective energy management strategy is designed and applied to achieve the power balance between the system units.

- The control systems design for the PV and battery storage systems and their related converters is accomplished in a systematic manner.

- The current study can be used as a base for designing different structures of HRES, in which more energy systems can be incorporated, such as fuel cells, diesel generators, and wave energy sources as well. This fact can be determined according to the load type and its requirements.

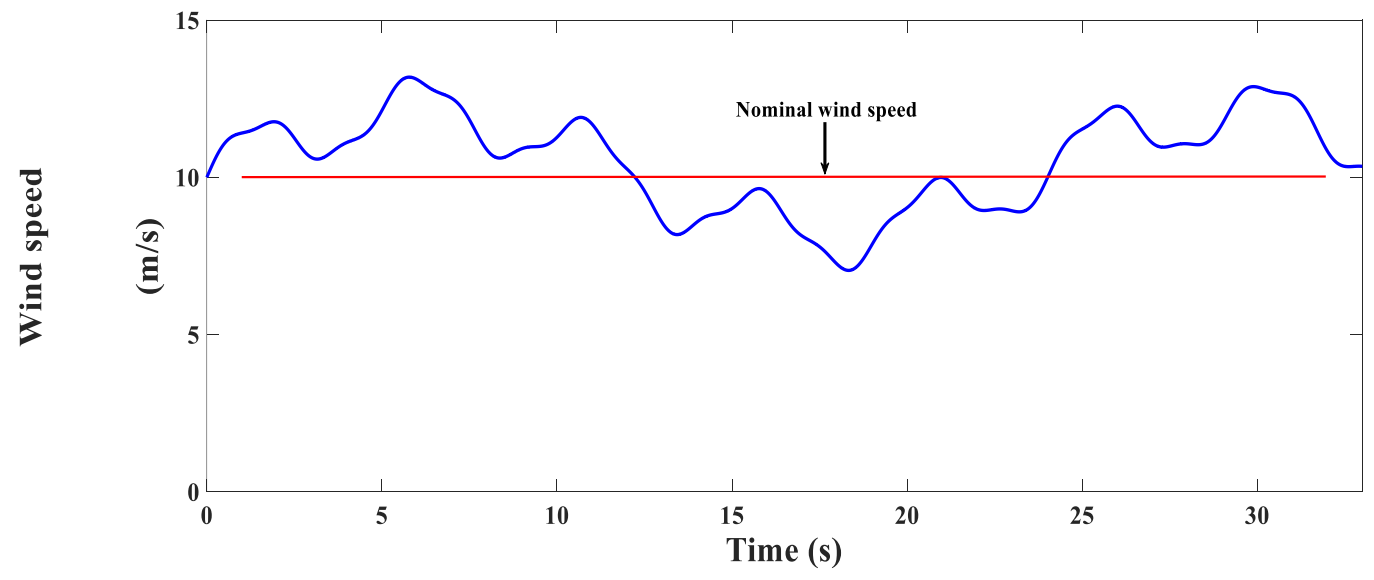

Fig. 17. Wind speed variation

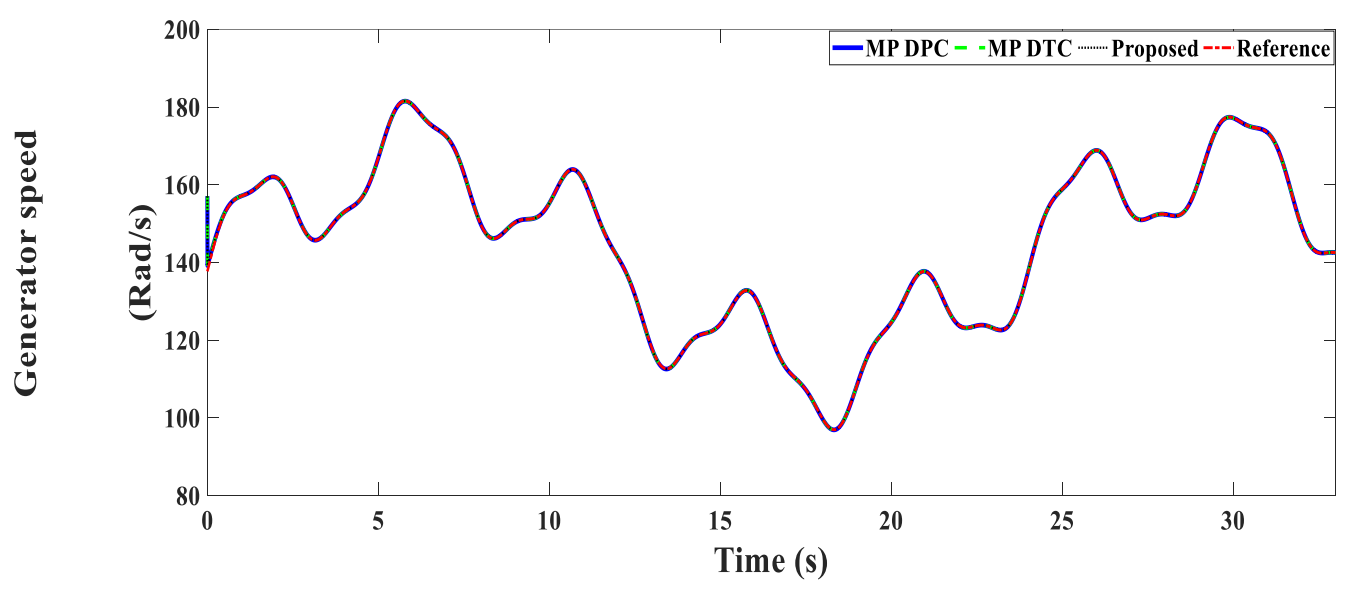

Fig. 18. Generator speed 


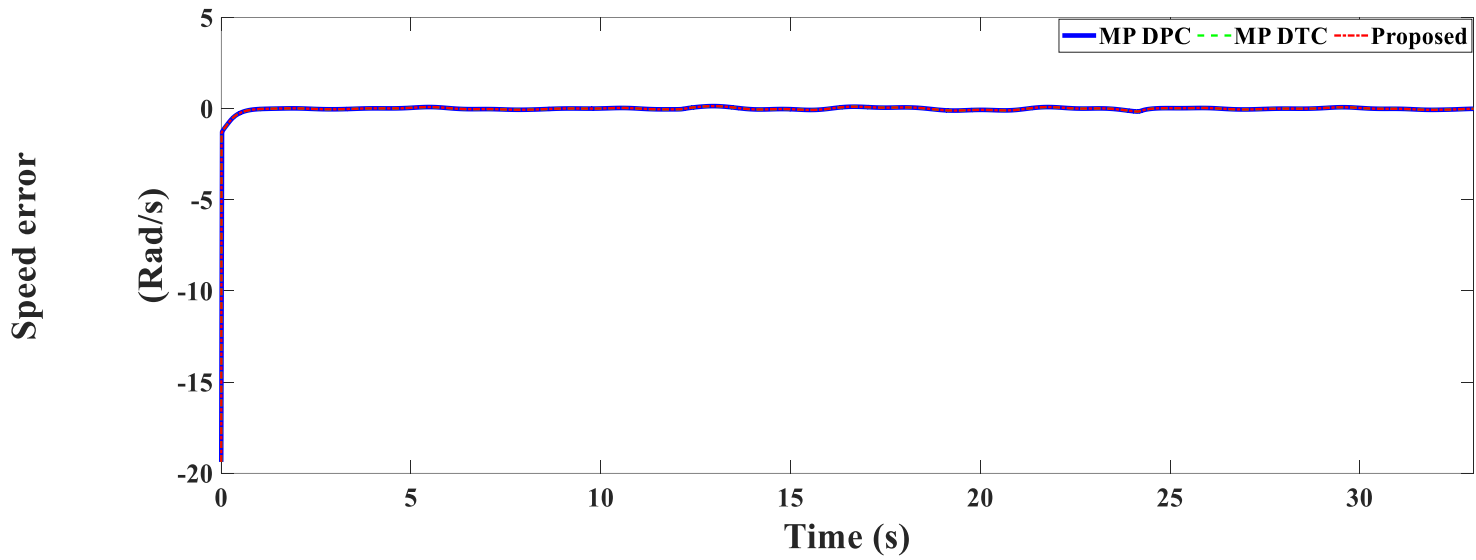

Fig. 19. Speed tracking error

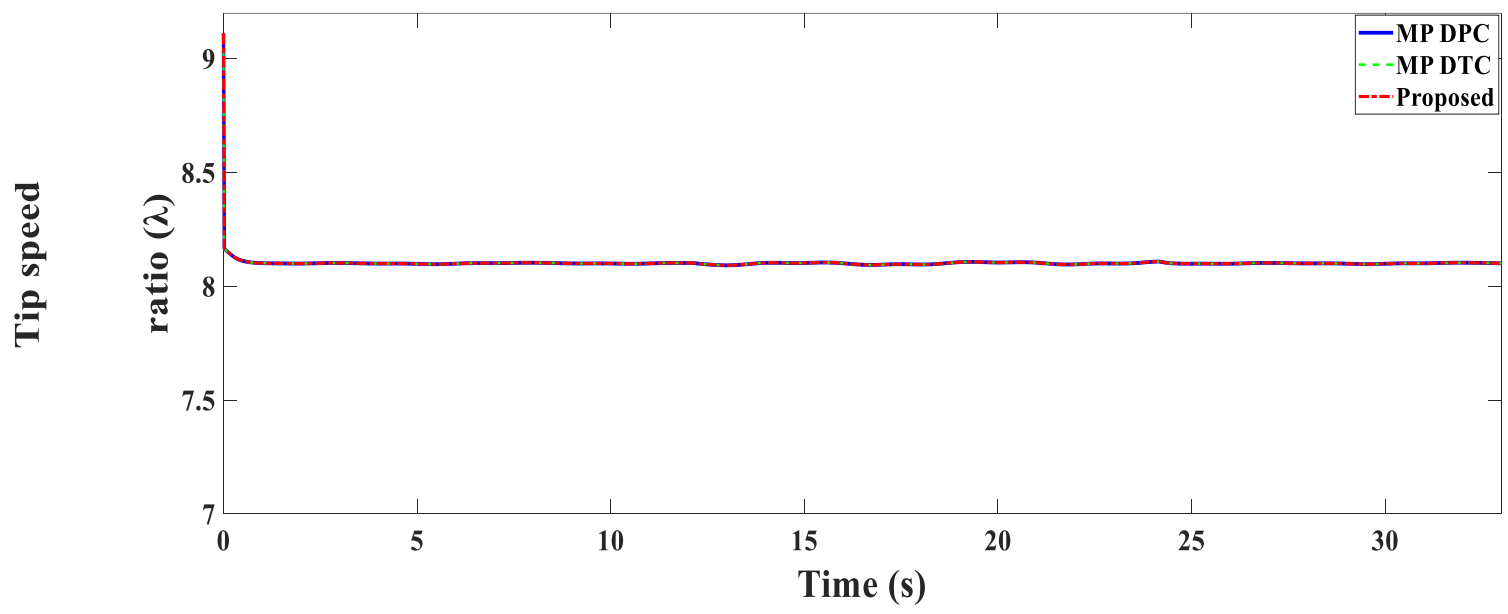

Fig. 20. Tip speed ratio

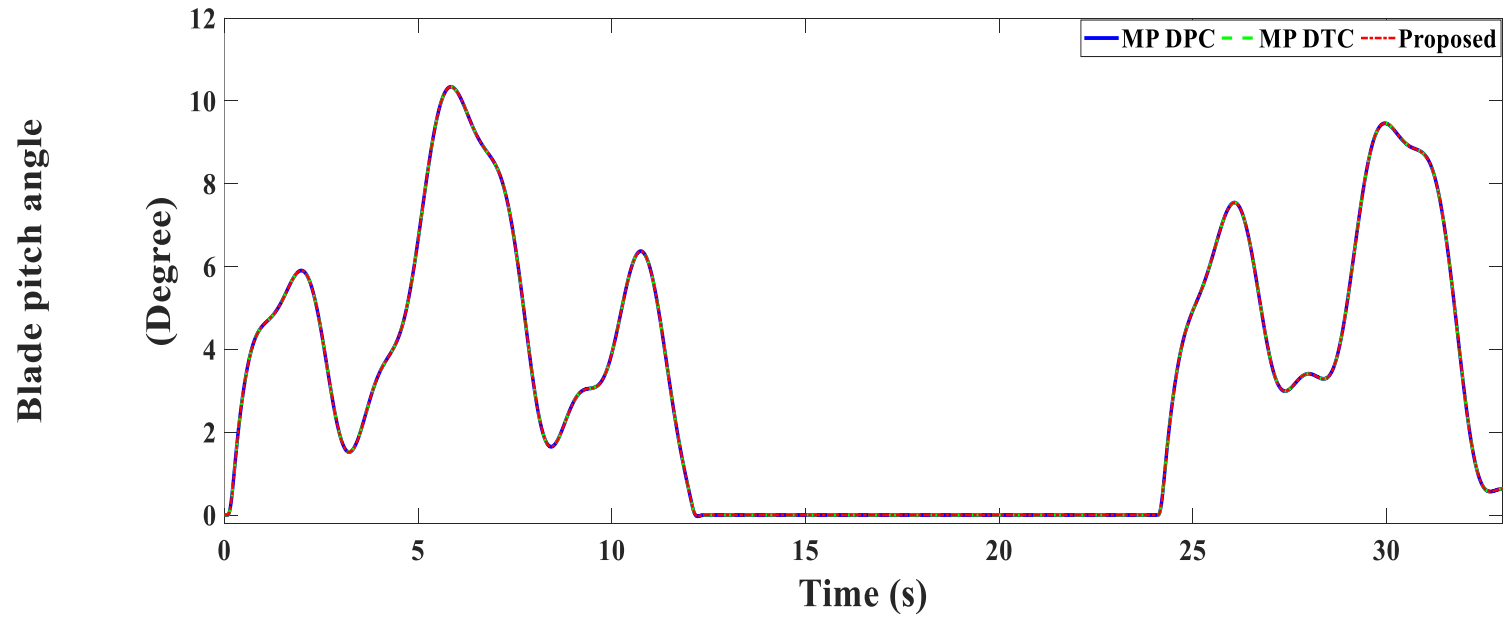

Fig. 21. Blade pitch angle 


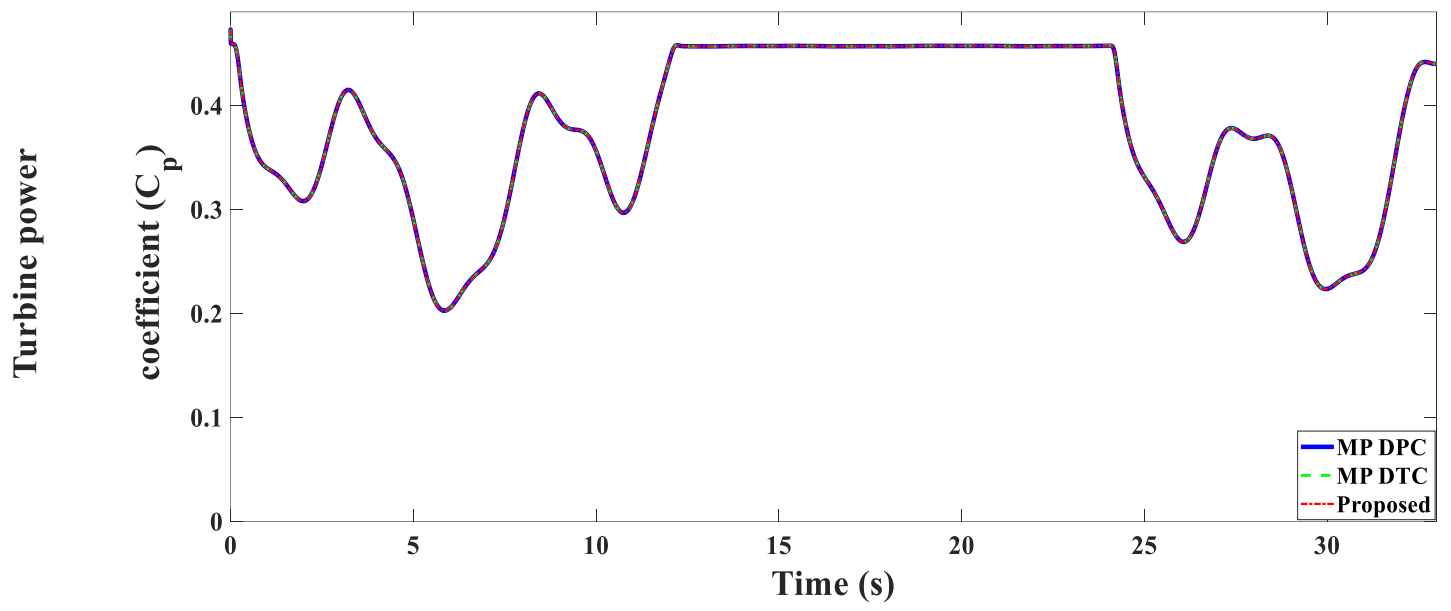

Fig. 22. Turbine power coefficient

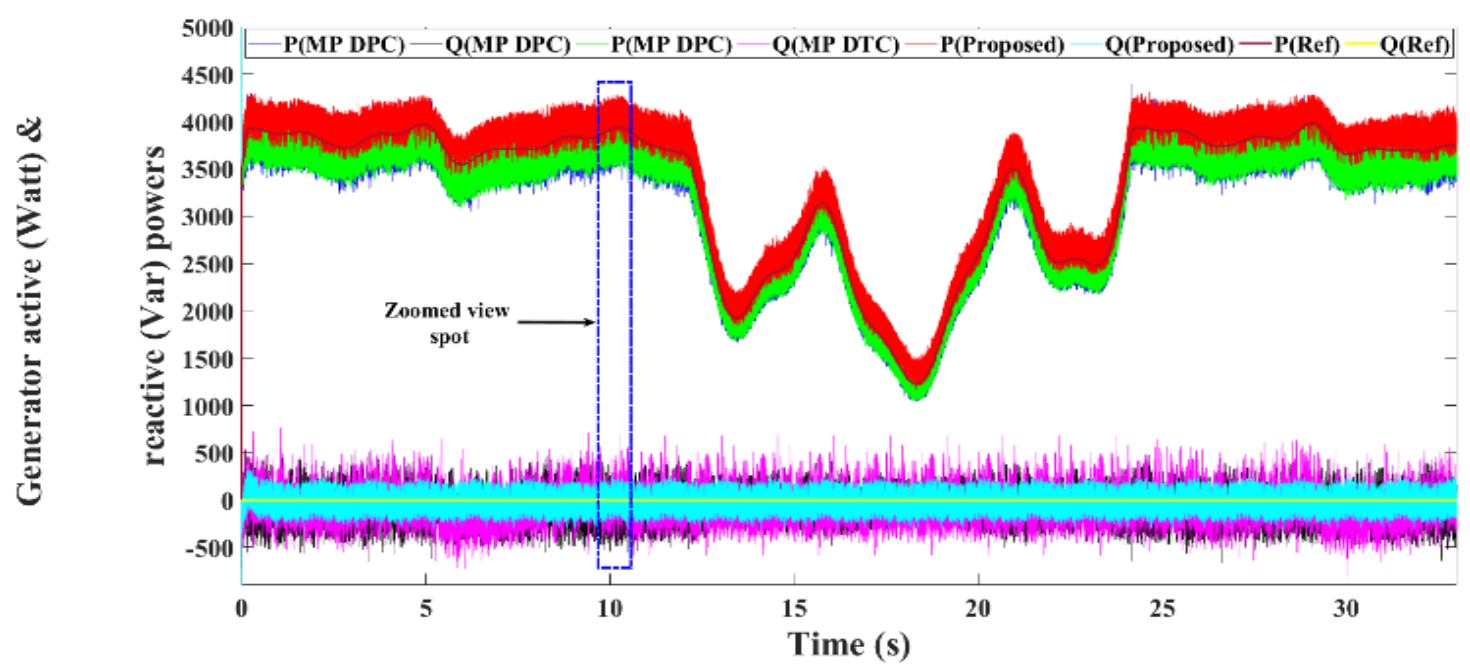

Fig. 23. $P M S G$ active and reactive power profiles

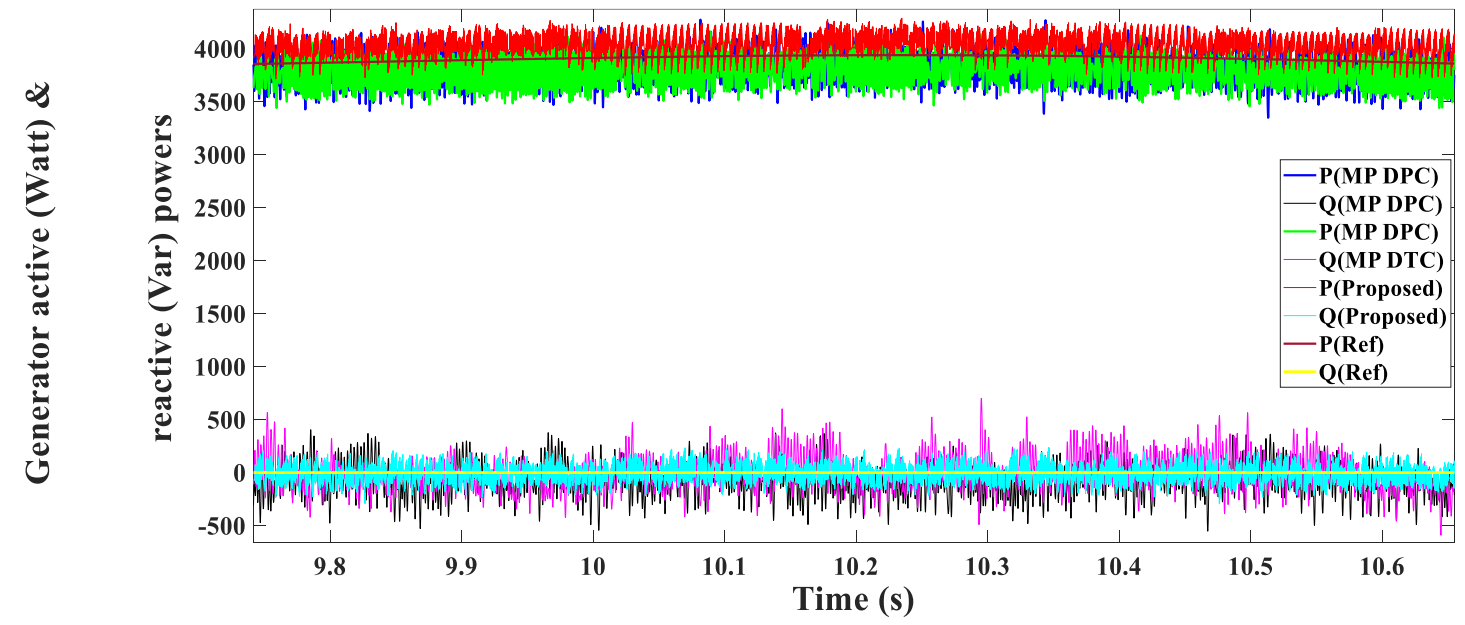

Fig. 24. Detailed view of PMSG active and reactive powers 


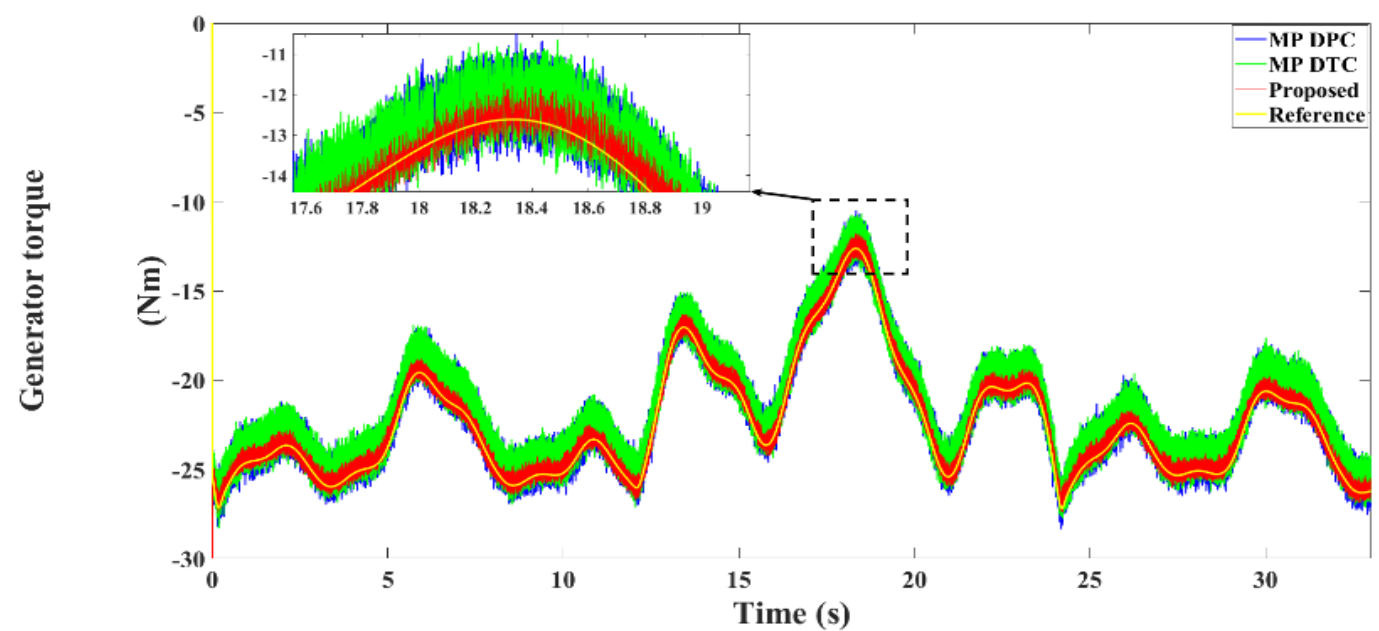

Fig. 25. Generator torque

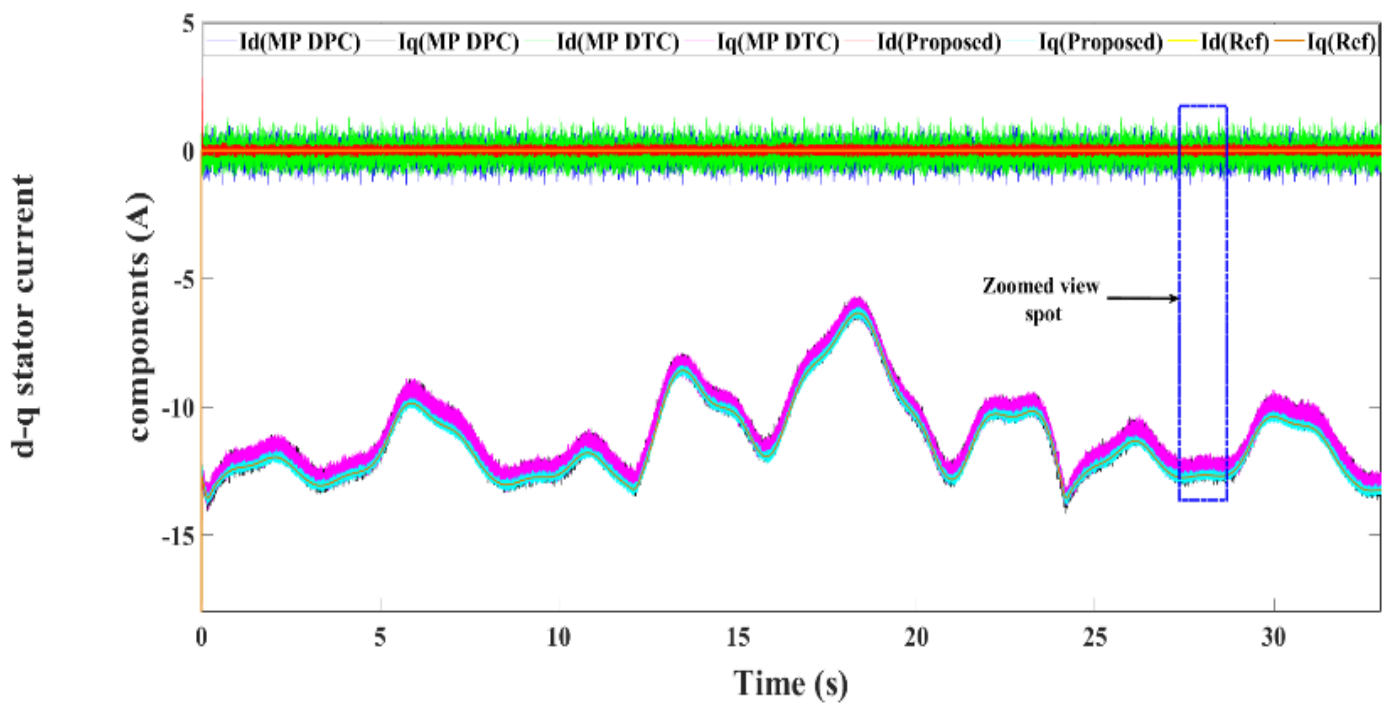

Fig. 26. The $d-q$ current components of PMSG

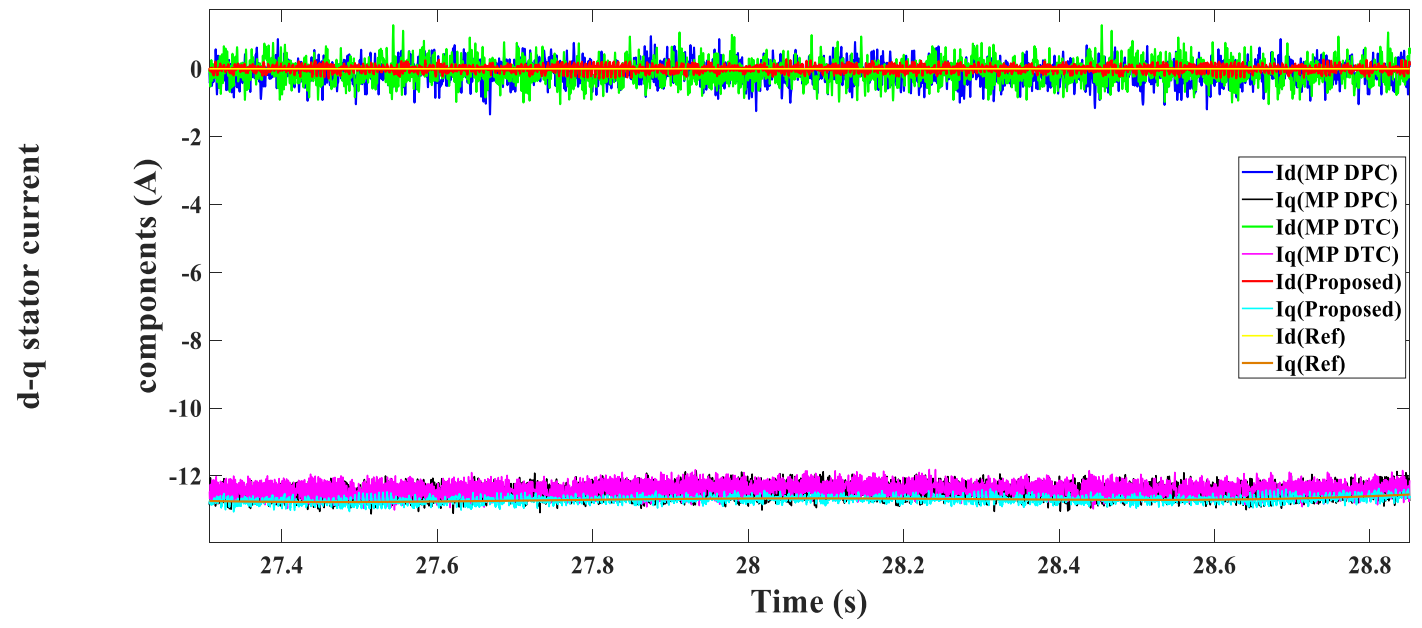

Fig. 27. Detailed view of $d-q$ stator current components 


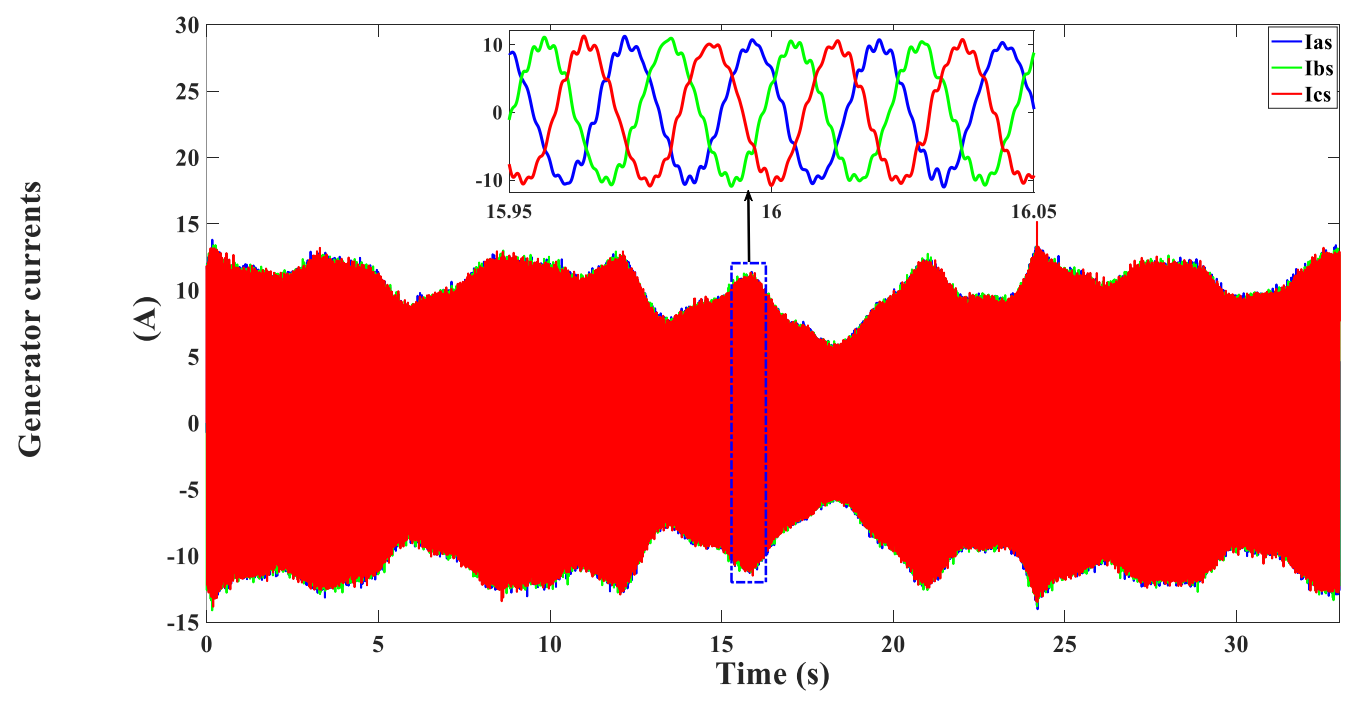

Fig. 28. Generated currents using MP DPC approach

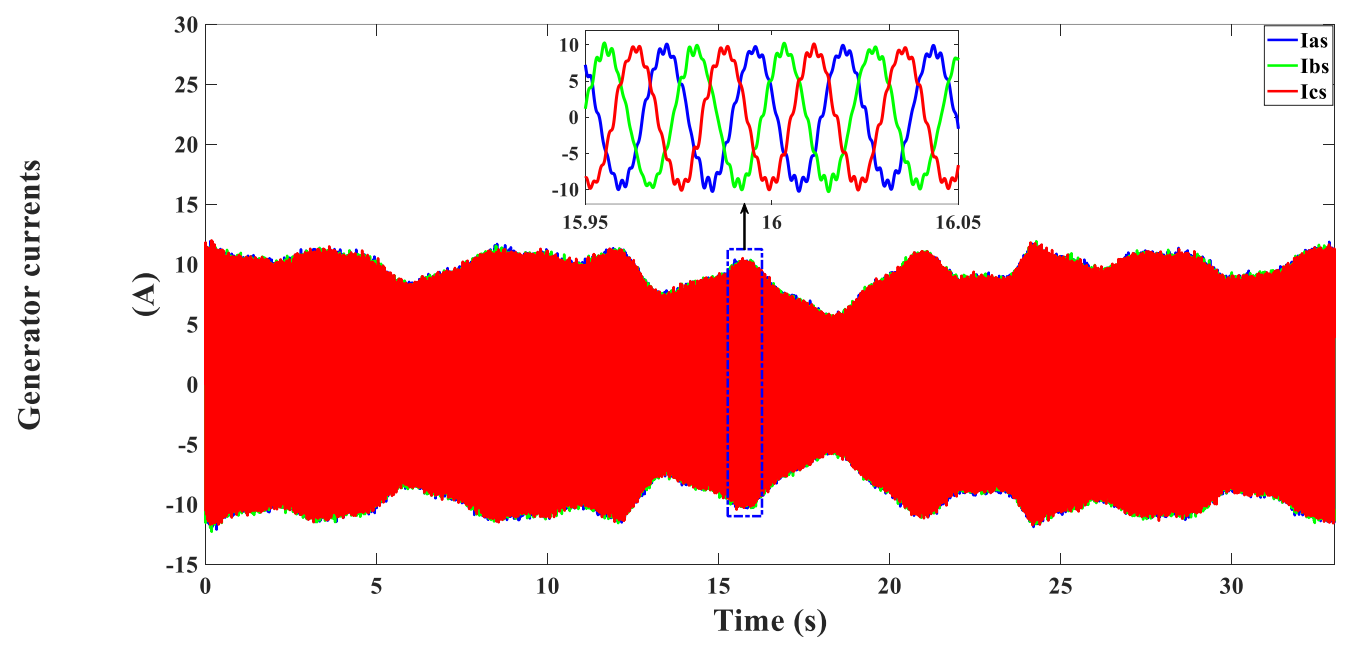

Fig. 29. Generated currents using MP DTC approach

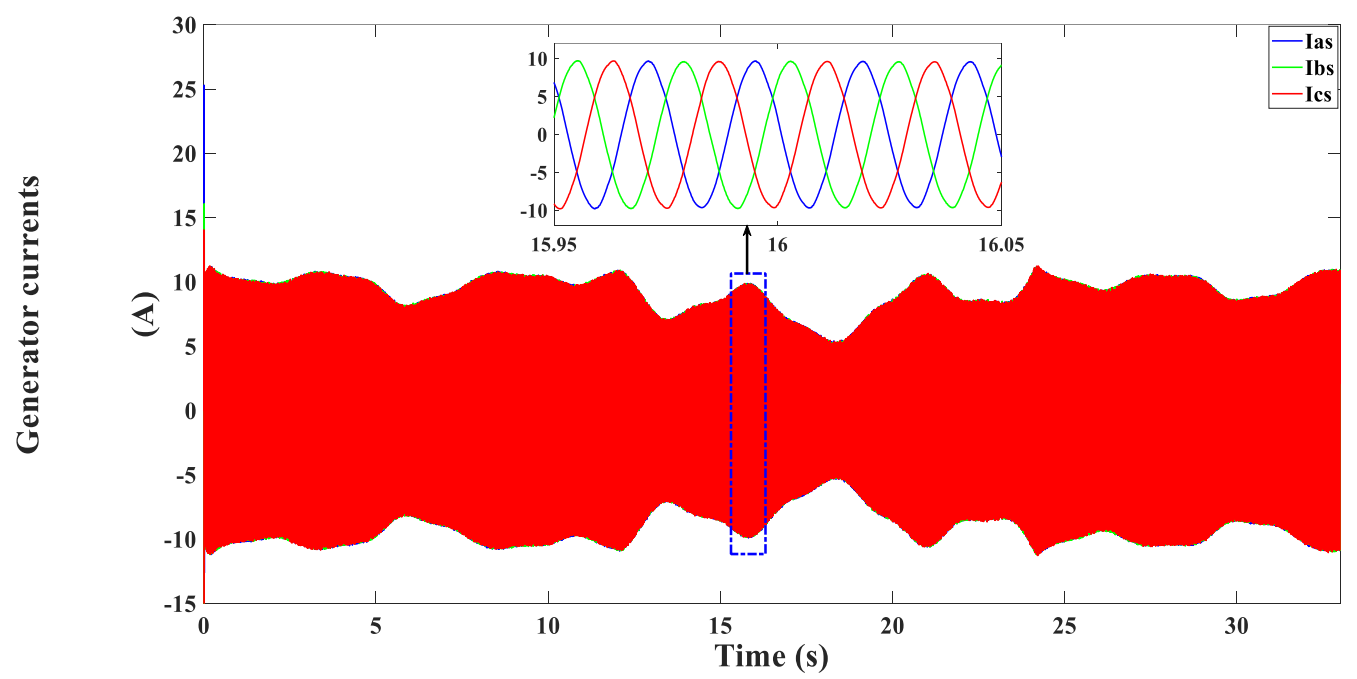

Fig. 30. Generated currents using proposed control approach 

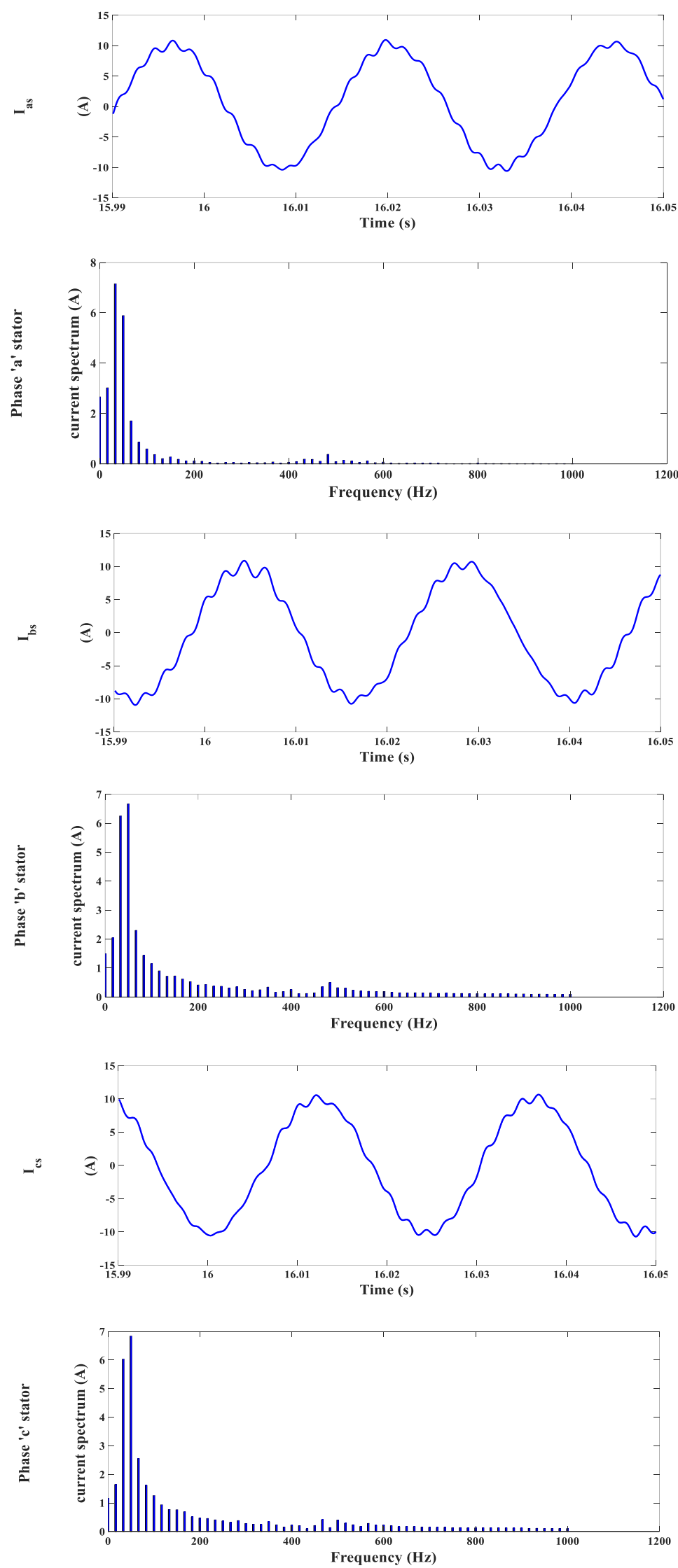

Fig. 31. Generated currents and the relevant spectrum analysis using MP DPC approach 

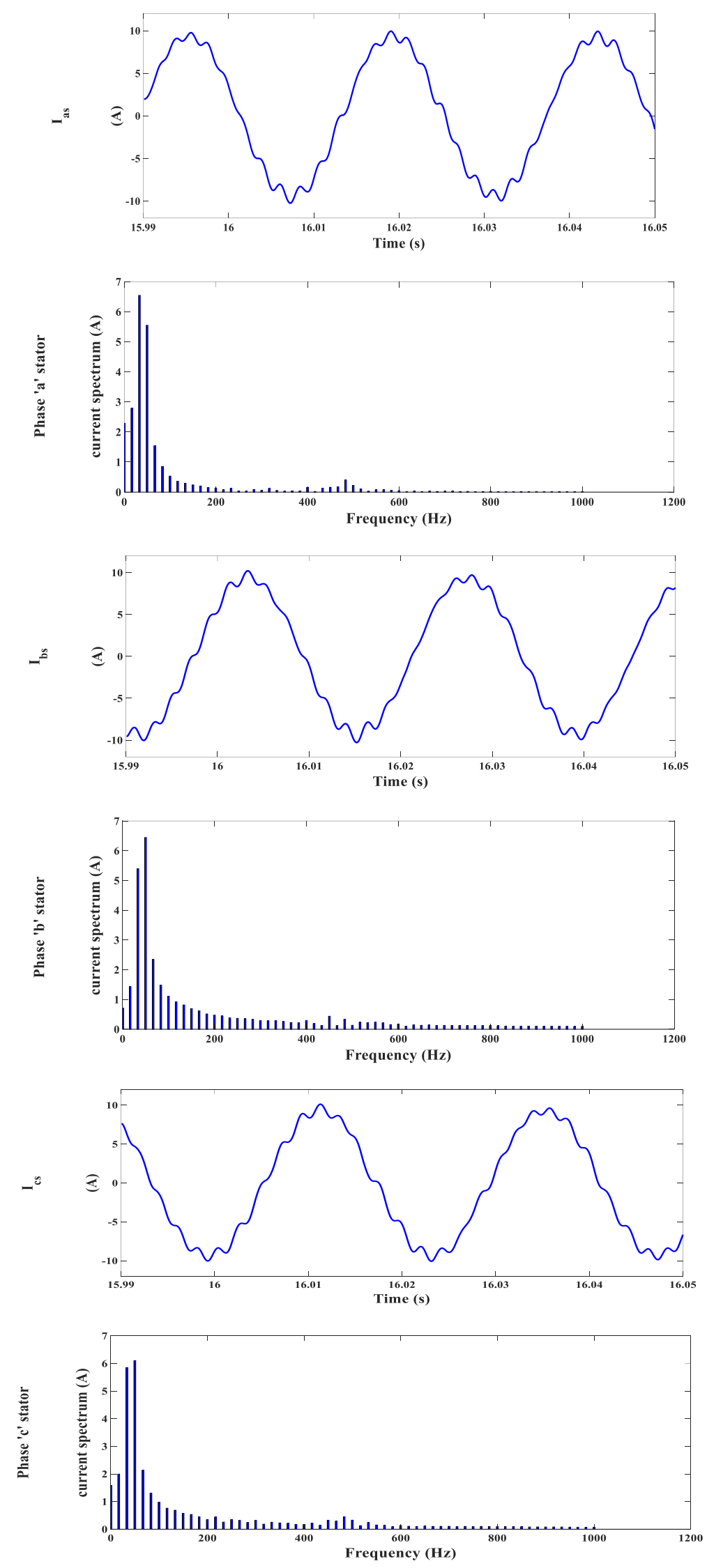

Fig. 32. Generated currents and the relevant spectrum analysis using MP DTC approach 

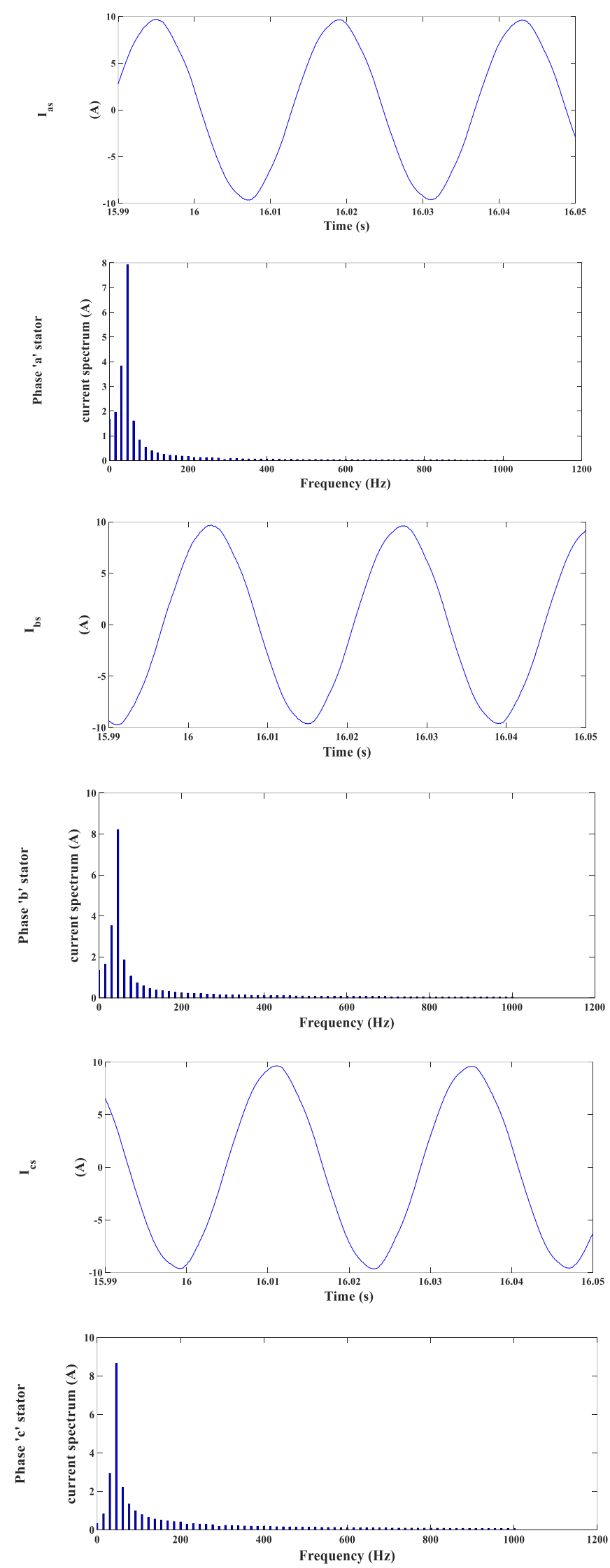

Fig. 33. Generated currents and the relevant spectrum analysis using proposed predictive control approach 

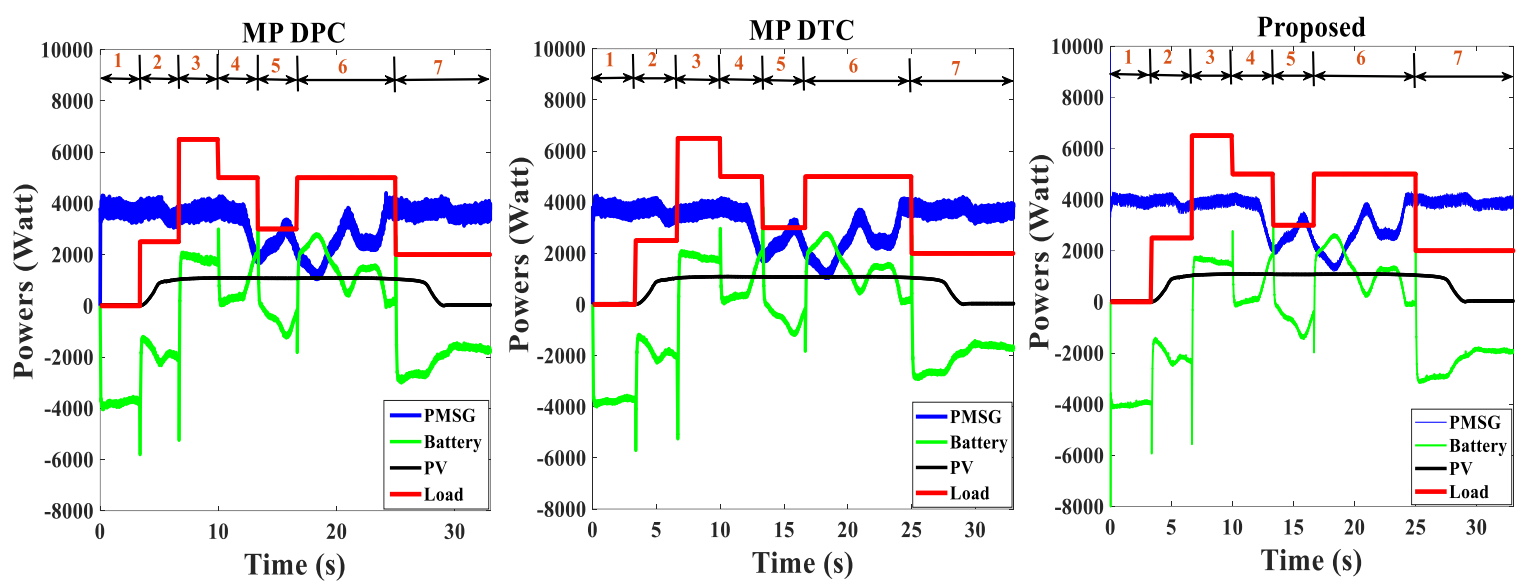

Fig. 34. Power flow in HRES system considering the three predictive control algorithms with PMSG
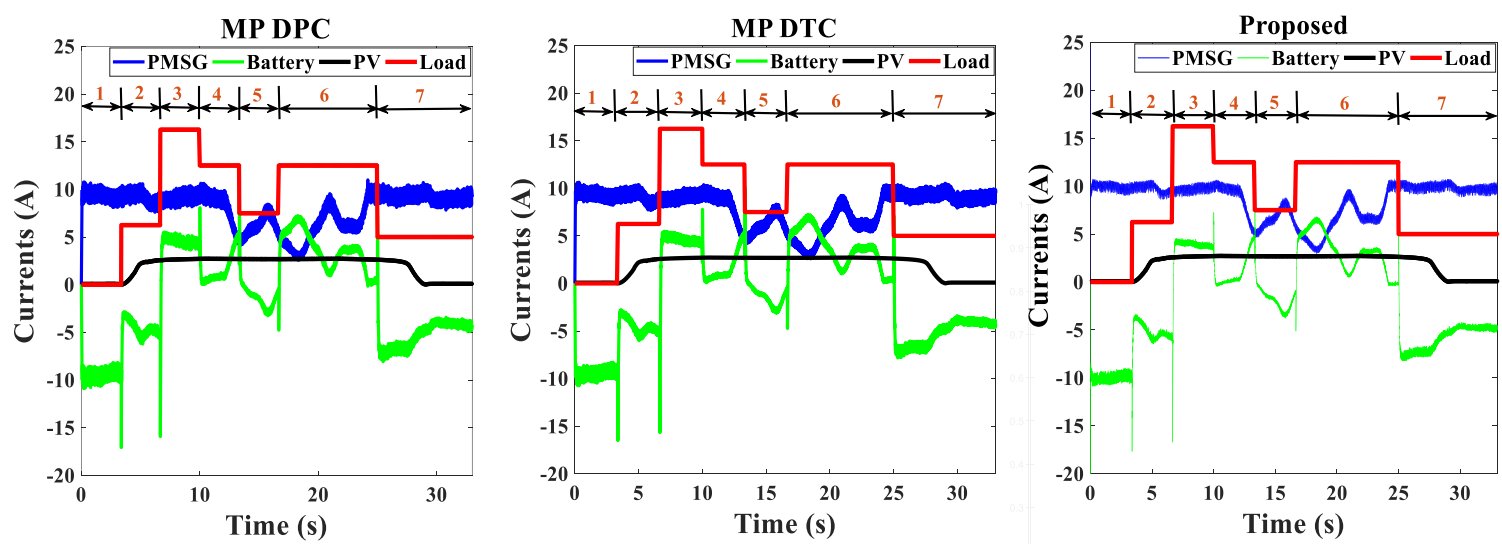

Fig. 35. Current flow in HRES system considering the three predictive control algorithms with PMSG

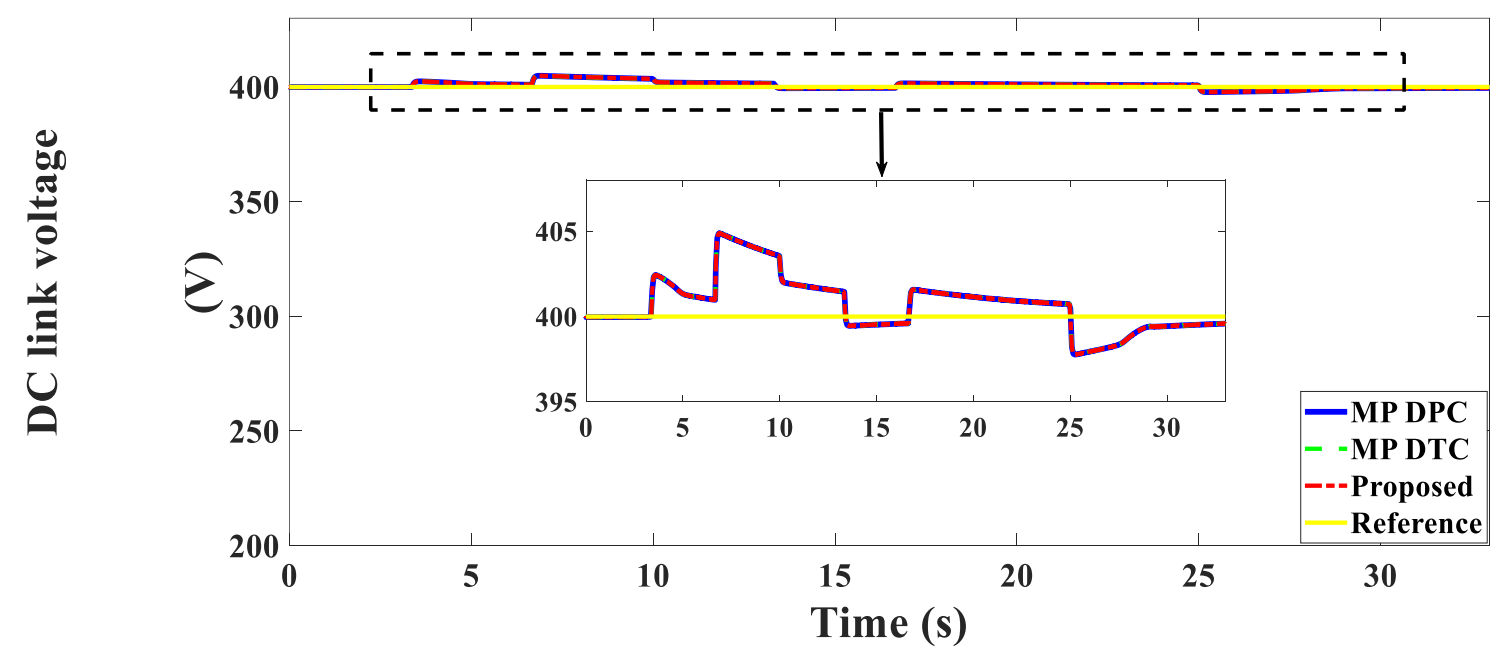

Fig. 36. DC link voltage profile 
Author Contribution: All authors contributed equally to the main contributor to this paper. All authors read and approved the final paper.

Acknowledgment: This work was made possible by a fellowship funded by the Egyptian Mission Sector at Ministry of Higher Education of the Arab Republic of Egypt.

Conflicts of Interest: The authors declare no conflict of interest.

\section{Appendix A}

Table A. 1. Parameters of wind turbine generation system

\begin{tabular}{cccc}
\hline Parameter & Value & Parameter & Value \\
\hline$r$ & $2 \mathrm{~m}$ & $p$ & 4 \\
$C_{\text {Pmax }}$ & 0.472 & $R$ & $0.82 \Omega$ \\
$\lambda_{\text {opt }}$ & 8.1 & $L_{s}$ & $15.1 \mathrm{mH}$ \\
$P_{\text {nom }}$ & $3.9 \mathrm{KW}$ & $\psi_{f}$ & $0.5 \mathrm{Vs}$ \\
$\Omega_{w, n o m}$ & $10 \mathrm{~m} / \mathrm{s}$ & $C_{d c}$ & $2200 \mu \mathrm{F}$ \\
$\mathrm{G}$ & 3.83 & $T_{s}$ & $100 \mu \mathrm{s}$ \\
\hline
\end{tabular}

Table A. 2. PV array specifications

\begin{tabular}{cc}
\hline Variable & Value \\
\hline Nominal power & $1 \mathrm{KW}$ \\
Open circuit voltage & $21 \mathrm{~V}$ \\
Short circuit current & $8 \mathrm{~A}$ \\
No of series-connected modules per string & 2 \\
No parallel strings & 4 \\
\hline
\end{tabular}

Table A. 3. Battery specifications

\begin{tabular}{cccc}
\hline Parameter & Value & Parameter & Value \\
\hline$R_{t}$ & $2.75 \mathrm{~m} \Omega$ & $L_{b a t}$ & $30 \mathrm{mH}$ \\
$R_{e}$ & $3.75 \mathrm{~m} \Omega$ & Capacity & $50 \mathrm{Ah}$ \\
$R_{s u}$ & $3.75 \mathrm{~m} \Omega$ & Rated voltage & $240 \mathrm{~V}$ \\
$C_{b u}$ & $8.8373 \mathrm{~F}$ & DOD $(\%)$ & $60 \%$ \\
$C_{s u}$ & $82.1 \mathrm{mF}$ & $\eta_{b a t} \%$ & $85 \%$ \\
\hline
\end{tabular}

\section{References}

[1] M. Nurunnabi, N. K. Roy, E. Hossain, and H. R. Pota, "Size Optimization and Sensitivity Analysis of Hybrid Wind/PV Micro-Grids- A Case Study for Bangladesh," IEEE Access, vol. 7, pp. 150120-150140, 2019, https://doi.org/10.1109/ACCESS.2019.2945937.

[2] A. Sangwongwanich, Y. Yang, and F. Blaabjerg, "Development of flexible active power control strategies for grid-connected photovoltaic inverters by modifying MPPT algorithm," Proceedings of the IEEE $3^{\text {rd }}$ International Future Energy Electronics Conference and ECCE Asia, 2017, pp. 87-92, https://doi.org/10.1109/IFEEC.2017.7992423.

[3] B. Mohandes, M. Wahbah, M. S. E. Moursi, and T. H. M. El-Fouly, "Renewable Energy Management System: Optimum Design and Hourly Dispatch," IEEE Transactions on Sustainable Energy, vol. 12, no. 3, pp. 1615-1628, July 2021, https://doi.org/10.1109/TSTE.2021.3058252.

[4] A. Jahid, M. K. H. Monju, M. E. Hossain, and M. F. Hossain, "Renewable Energy Assisted Cost Aware Sustainable Off-Grid Base Stations with Energy Cooperation," IEEE Access, vol. 6, pp. 60900-60920, 2018, https://doi.org/10.1109/ACCESS.2018.2874131.

[5] A. N. Akpolat, Y. Yang, F. Blaabjerg, E. Dursun, and A. E. Kuzucuoğlu, "Design Implementation and Operation of an Education Laboratory-Scale Microgrid," IEEE Access, vol. 9, pp. 57949-57966, 2021, https://doi.org/10.1109/ACCESS.2021.3072899.

[6] S. Pannala, N. Patari, A. K. Srivastava, and N. P. Padhy, "Effective Control and Management Scheme for Isolated and Grid Connected DC Microgrid," IEEE Transactions on Industry Applications, vol. 56, no. 6, pp. 6767-6780, Nov.-Dec. 2020, https://doi.org/10.1109/TIA.2020.3015819. 
[7] X. Kong, X. Liu, L. Ma, and K. Y. Lee, "Hierarchical distributed model predictive control of standalone wind/solar/battery power system," IEEE Trans. Syst. Man Cybern. Syst., vol. 49, pp. 1570-1581, 2019, https://doi.org/10.1109/TSMC.2019.2897646.

[8] W. Jing, C. H. Lai, S. H. Wallace, and M. L. Wong, "Battery-supercapacitor hybrid energy storage system in standalone DC microgrids: A review," IET Renew. Power Gener., vol. 11, pp. 461-469, 2017, https://doi.org/10.1049/iet-rpg.2016.0500.

[9] S. Angadi, U. R. Yaragatti, Y. Suresh and A. B. Raju, "Comprehensive review on solar, wind and hybrid wind-PV water pumping systems-an electrical engineering perspective," CPSS Transactions on Power Electronics and Applications, vol. 6, no. 1, pp. 1-19, 2021, https://doi.org/10.24295/CPSSTPEA.2021.00001.

[10] S. Pradhan, S. Murshid, B. Singh, and B. K. Panigrahi, "Performance Investigation of Multifunctional On-Grid Hybrid Wind-PV System with OASC and MAF-Based Control," IEEE Transactions on Power Electronics, vol. 34, no. 11, pp. 10808-10822, 2019, https://doi.org/10.1109/TPEL.2019.2900759.

[11] Q. Wu, Y. Sun, Z. Navid, and K. Samir, Modeling and Modern Control of Wind Power, John Wiley \& Sons: New York, NY, USA, 2018, https://doi.org/10.1002/9781119236382.

[12] Z. Zhang, J. Rodríguez and R. Kennel, "Advanced control strategies for direct-drive PMSG wind turbine systems: Direct predictive torque control approaches," CPSS Transactions on Power Electronics and Applications, vol. 2, no. 3, pp. 217-225, 2017, https://doi.org/10.24295/CPSSTPEA.2017.00020.

[13] Y. Zhu, R. Zhao, and J. Zhao, "Output power smoothing control for the PMSG based wind farm by using the allocation of the wind turbines," Proceedings of the 20th International Conference on Electrical Machines and Systems (ICEMS), 2017, pp. 1-6, https://doi.org/10.1109/ICEMS.2017.8055952.

[14] P. Gajewski and K. Pie, "Control of wind turbine system with PMSG for low voltage ride through," Proceedings of the International Symposium on Electrical Machines, 2018, pp. 1-6, https://doi.org/10.1109/ISEM.2018.8442464.

[15] W. Gul, Q. Gao and W. Lenwari, "Optimal Design of a 5-MW Double-Stator Single-Rotor PMSG for Offshore Direct Drive Wind Turbines," IEEE Transactions on Industry Applications, vol. 56, no. 1, pp. 216-225, Jan.-Feb. 2020, https://doi.org/10.1109/TIA.2019.2949545.

[16] Y. Mahmoud and W. Xiao, "Evaluation of Shunt Model for Simulating Photovoltaic Modules," IEEE Journal of Photovoltaics, vol. 8, no. 6, pp. 1818-1823, Nov. 2018, https://doi.org/10.1109/JPHOTOV.2018.2869493.

[17] J. -E. Hernández-Díez, C. -F. Méndez-Barrios, S. -I. Niculescu and E. Bárcenas-Bárcenas, "A Current Sensorless Delay-Based Control Scheme for MPPT-Boost Converters in Photovoltaic Systems," IEEE Access, vol. 8, pp. 174449-174462, 2020, https://doi.org/10.1109/ACCESS.2020.3024566.

[18] H. Farhangi and G. Joos, Microgrid Planning and Design: A Concise Guide, John Wiley, and Sons, Ltd., New York, NY, USA, 2019, https://doi.org/10.1002/9781119453550.

[19] R. Fuentes, D. Rojas, M. Rivera, J. Riveros, J. Muñoz and P. Wheeler, "Control strategies of photovoltaic systems," 2021 IEEE CHILEAN Conference on Electrical, Electronics Engineering, Information and $\begin{array}{lllll}\text { Communication } & \text { Technologies } & \text { (CHILECON), } & 2021, & \text { pp. }\end{array}$ https://doi.org/10.1109/CHILECON54041.2021.9702993.

[20] W. E. Vanco, F. B. Silva, F. A. S. Goncalves, and C. A. Bissochi, "Evaluation of the Capacitor Bank Design for Self-Excitation in Induction Generators," IEEE Latin America Transactions, vol. 16, no. 2, pp. 482-488, Feb. 2018, https://doi.org/10.1109/TLA.2018.8327403.

[21] K. Teng, Z. Lu, J. Long, Y. Wang, and A. P. Roskilly, "Voltage Build-Up Analysis of Self-Excited Induction Generator With Multi-Timescale Reduced-Order Model," IEEE Access, vol. 7, pp. 4800348012, 2019, https://doi.org/10.1109/ACCESS.2019.2902977.

[22] F. Meng, D. Sun, K. Zhou, J. Wu, F. Zhao, and L. Sun, "A Sub-Synchronous Oscillation Suppression Strategy for Doubly Fed Wind Power Generation System," IEEE Access, vol. 9, pp. 83482-83498, 2021, https://doi.org/10.1109/ACCESS.2021.3087638. 
[23] M. A. Mossa, H. Echeikh, A.A. Diab, N.V. Quynh, "Effective Direct Power Control for a Sensor-Less Doubly Fed Induction Generator with a Losses Minimization Criterion," Electronics, vol. 9, p. 1269, 2020, https://doi.org/10.3390/electronics9081269.

[24] M. A. Mossa, A. Saad Al-Sumaiti, T. Duc Do and A. A. Zaki Diab, "Cost-Effective Predictive Flux Control for a Sensorless Doubly Fed Induction Generator," IEEE Access, vol. 7, pp. 172606-172627, 2019, https://doi.org/10.1109/ACCESS.2019.2951361.

[25] M. A. Mossa and S. Bolognani, "Predictive Power Control for a Linearized Doubly Fed Induction Generator Model," 2019 21st International Middle East Power Systems Conference (MEPCON), 2019, pp. 250-257, https://doi.org/10.1109/MEPCON47431.2019.9008085.

[26] A. M. I. Mohamad, M. Fakhari Moghaddam Arani, and Y. A. I. Mohamed, "Investigation of Impacts of Wind Source Dynamics and Stability Options in DC Power Systems with Wind Energy Conversion Systems," IEEE Access, vol. 8, pp. 18270-18283, 2020, https://doi.org/10.1109/ACCESS.2020.2966363.

[27] M. K. K. Prince, M. T. Arif, A. Gargoom, A. M. T. Oo, M. E. Haque, "Modeling, Parameter Measurement, and Control of PMSG based Grid-connected Wind Energy Conversion System," J. Mod. Power Syst. Clean Energy, vol. 9, pp. 1054-1065, 2021, https://doi.org/10.35833/MPCE.2020.000601.

[28] M. A. Mossa, O. Gam, N. Bianchi, N., "Dynamic Performance Enhancement of a Renewable Energy System for Grid Connection and Stand-alone Operation with Battery Storage," Energies, vol. 15, p. 1002, 2022, https://doi.org/10.3390/en15031002.

[29] R. Basak, G. Bhuvaneswari and R. R. Pillai, "Low-Voltage Ride-Through of a Synchronous GeneratorBased Variable Speed Grid-Interfaced Wind Energy Conversion System," IEEE Transactions on Industry Applications, vol. 56, no. 1, pp. 752-762, 2020, https://doi.org/10.1109/TIA.2019.2946125.

[30] I. Jlassi and A. J. M. Cardoso, "Fault-Tolerant Back-to-Back Converter for Direct-Drive PMSG Wind Turbines Using Direct Torque and Power Control Techniques," IEEE Transactions on Power Electronics, vol. 34, no. 11, pp. 11215-11227, 2019, https://doi.org/10.1109/TPEL.2019.2897541.

[31] S. Y. Yip, H. S. Che, C. P. Tan, and W. T. Chong, "A Lookup Table Model Predictive Direct Torque Control of Permanent-Magnet Synchronous Generator Based on Vienna Rectifier," IEEE Journal of Emerging and Selected Topics in Power Electronics, vol. 8, no. 2, pp. 1208-1222, June 2020, https://doi.org/10.1109/JESTPE.2019.2900917.

[32] P. J. D. S. Neto, A. C. Pinto, D. S. B. T. André, and E. R. Filho, "A Proposal to Control Active and Reactive Power in Distributed Generation Systems Using Small Wind Turbines," IEEE Latin America Transactions, vol. 18, no. 10, pp. 1699-1706, October 2020, https://doi.org/10.1109/TLA.2020.9387640.

[33] J. Torres, R. Peña, J. Tapia, J. Riedemann and C. Pesce, "Direct power control of an Axial Flux Permanent Magnet Synchronous machine," 2017 IEEE Southern Power Electronics Conference (SPEC), 2017, pp. 1-6, https://doi.org/10.1109/SPEC.2017.8333643.

[34] T. P. Teixeira and C. L. T. Borges, "Operation Strategies for Coordinating Battery Energy Storage with Wind Power Generation and Their Effects on System Reliability," Journal of Modern Power Systems and Clean Energy, vol. 9, no. 1, pp. 190-198, January 2021, https://doi.org/10.35833/MPCE.2019.000492.

[35] L. Bigarelli, M. di Benedetto, A. Lidozzi, L. Solero, S. A. Odhano, and P. Zanchetta, "PWM-Based Optimal Model Predictive Control for Variable Speed Generating Units," IEEE Transactions on Industry Applications, vol. 56, no. 1, pp. 541-550, Jan.-Feb. 2020, https://doi.org/10.1109/TIA.2019.2955662.

[36] H. Wang, J. Yang, Z. Chen, W. Ge, Y. Ma, Z. Xing, and L. Yang, "Model Predictive Control of PMSGBased Wind Turbines for Frequency Regulation in an Isolated Grid," IEEE Transactions on Industry Applications, vol. 54, no. 4, pp. 3077-3089, July-Aug. 2018, https://doi.org/10.1109/TIA.2018.2817619.

[37] Z. Zhang, H. Fang, F. Gao, J. Rodríguez, and R. Kennel, "Multiple-Vector Model Predictive Power Control for Grid-Tied Wind Turbine System With Enhanced Steady-State Control Performance," IEEE Transactions on Industrial Electronics, vol. 64, no. 8, pp. 6287-6298, Aug. 2017, https://doi.org/10.1109/TIE.2017.2682000.

[38] I. Jlassi and A. J. M. Cardoso, "Enhanced and Computationally Efficient Model Predictive Flux and Power Control of PMSG Drives for Wind Turbine Applications," IEEE Transactions on Industrial Electronics, vol. 68, no. 8, pp. 6574-6583, Aug. 2021, https://doi.org/10.1109/TIE.2020.3005095. 
[39] H. Mahmoudi, M. Aleenejad, P. Moamaei, and R. Ahmadi, "Fuzzy adjustment of weighting factor in model predictive control of permanent magnet synchronous machines using current membership functions," 2016 IEEE Power and Energy Conference at Illinois (PECI), 2016, pp. 1-5, https://doi.org/10.1109/PECI.2016.7459225.

[40] P. R. U. Guazzelli, W. C. de Andrade Pereira, C. M. R. de Oliveira, A. G. de Castro, and M. L. de Aguiar, "Weighting Factors Optimization of Predictive Torque Control of Induction Motor by Multiobjective Genetic Algorithm," IEEE Transactions on Power Electronics, vol. 34, no. 7, pp. 6628-6638, July 2019, https://doi.org/10.1109/TPEL.2018.2834304.

[41] M. A. Mossa and Y. Mohamed, "Novel Scheme for Improving the Performance of a Wind Driven Doubly Fed Induction Generator during Grid Fault," Wind. Eng., vol. 36, pp. 305-334, 2012, https://doi.org/10.1260/0309-524X.36.3.305.

[42] M. A. Mossa, H. Echeikh, and A. Iqbal, "Enhanced control technique for a sensor-less wind driven doubly fed induction generator for energy conversion purpose," Energy Rep., vol. 7, pp. 5815-5833, 2021, https://doi.org/10.1016/j.egyr.2021.08.183.

[43] M. M. Islam and D. Chowdhury, "Advanced and comprehensive control methods in wind energy systems," Emerging Power Converters For Renewable Energy And Electric Vehicles, Taylor \& Francis: Abingdon, UK, 2021, pp. 191-224, https://doi.org/10.1201/9781003058472-6.

[44] K. Venkatesan and U. Govindarajan, "Optimal power flow control of hybrid renewable energy system with energy storage: A Woann strategy," J. Renew. Sustain. Energy, vol. 11, p. 015501, 2018, https://doi.org/10.1063/1.5048446.

[45] T. Mesbahi, N. Rizoug, P. Bartholomeüs, R. Sadoun, F. Khenfri and P. Le Moigne, "Dynamic Model of Li-Ion Batteries Incorporating Electrothermal and Ageing Aspects for Electric Vehicle Applications," IEEE Transactions on Industrial Electronics, vol. 65, no. 2, pp. 1298-1305, Feb. 2018, https://doi.org/10.1109/TIE.2017.2714118.

[46] A. Küçüker, T. Kamal, S. Z. Hassan, H. Li, G. M. Mufti, and M. Waseem, "Design and control of photovoltaic/wind/battery based microgrid system," 2017 International Conference on Electrical Engineering (ICEE), 2017, pp. 1-6, https://doi.org/10.1109/ICEE.2017.7893445.

[47] B. S. Bhangu, P. Bentley, D. A. Stone, and C. M. Bingham, "Nonlinear observers for predicting state-ofcharge and state-of-health of lead-acid batteries for hybrid-electric vehicles," IEEE Transactions on Vehicular Technology, vol. 54, no. 3, pp. 783-794, May 2005, https://doi.org/10.1109/TVT.2004.842461.

[48] V. Yaramasu and B. Wu, Model Predictive Control of Wind Energy Conversion Systems, John Wiley \& Sons, Ltd.: New Jersey, NJ, USA, 2017, https://doi.org/10.1002/9781119082989.

[49] M. A. Mossa, T. D. Do, A. Al-Sumaiti, N. V. Quynh, and A. A. Diab, "Effective Model Predictive Voltage Control for a Sensorless Doubly Fed Induction Generator," IEEE Can. J. Electr. Comput. Eng. 2021, vol. 44, pp. 50-64, https://doi.org/10.1109/ICJECE.2020.3018495.

[50] O. Krishan and S. Suhan, "A novel control strategy for a hybrid energy storage system in a gridindependent hybrid renewable energy system," Int. Trans. Electr. Energy Syst., vol. 30, p. e12262, 2020, https://doi.org/10.1002/2050-7038.12262.

[51] P. S. Kumar, R. P. S. Chandrasena, and K. V. Sam Moses Babu, "Design and Development of Hybrid Wind-Solar-Battery Power Generation System using SVPWM Based Multilevel Inverter for Grid Connected Application," 2020 IEEE PES/IAS PowerAfrica, 2020, pp. 1-5, https://doi.org/10.1109/PowerAfrica49420.2020.9219987. 